\title{
Interface structure and flux laws in a natural double-diffusive layering
}

Tobias Sommer, ${ }^{1,2}$ Jeffrey R. Carpenter, ${ }^{1,3}$ Martin Schmid, ${ }^{1}$ Rolf G. Lueck, ${ }^{4}$ Michael Schurter, ${ }^{1}$ and Alfred Wüest ${ }^{1,2,5}$

Received 31 May 2013; revised 4 October 2013; accepted 18 October 2013; published 15 November 2013.

[1] The diffusive regime of double-diffusive convection generates staircases consisting of thin high-gradient interfaces sandwiched between convectively mixed layers. Simultaneous microstructure measurements of both temperature and conductivity from the staircases in Lake Kivu are used to test flux laws and theoretical models for double diffusion. Density ratios in Lake Kivu are between one and ten and mixed layer thicknesses on average $0.7 \mathrm{~m}$. The larger interface thickness of temperature (average $9 \mathrm{~cm}$ ) compared to dissolved substances $(6 \mathrm{~cm})$ confirms the boundary-layer structure of the interface. Our observations suggest that the boundary-layer break-off cannot be characterized by a single critical boundary-layer Rayleigh number, but occurs within a range of $\mathrm{O}\left(10^{2}\right)$ to $\mathrm{O}\left(10^{4}\right)$. Heat flux parameterizations which assume that the Nusselt number follows a power law increase with the Rayleigh number Ra are tested for their exponent $\eta$. In contrast to the standard estimate $\eta=1 / 3$, we found $\eta=0.20 \pm 0.03$ for density ratios between two and six. Therefore, we suggest a correction of heat flux estimates which are based on $\eta=1 / 3$. The magnitude of the correction depends on $\mathrm{Ra}$ in the system of interest. For Lake Kivu (average heat flux $0.10 \mathrm{~W} \mathrm{~m}^{-2}$ ) with $\mathrm{Ra}=\mathrm{O}\left(10^{8}\right)$, corrections are marginal. In the Arctic Ocean with $\mathrm{Ra}=\mathrm{O}\left(10^{8}\right)$ to $\mathrm{O}\left(10^{12}\right)$, however, heat fluxes can be overestimated by a factor of four.

Citation: Sommer, T., J. R. Carpenter, M. Schmid, R. G. Lueck, M. Schurter, and A. Wüest (2013), Interface structure and flux laws in a natural double-diffusive layering, J. Geophys. Res. Oceans, 118, 6092-6106, doi:10.1002/2013JC009166.

\section{Introduction}

[2] The vertical transport of heat and dissolved substances, such as salt, nutrients, and oxygen, is of high importance in natural water bodies. Double diffusion enhances the vertical transport within a stratified water body by transforming gradual density gradients into staircases of convectively mixed layers, separated by high-gradient and gravitationally stable interfaces (Figure 1). Such staircases can develop when two agents that diffuse at different rates, contribute in opposing ways to the vertical density gradient [Schmitt, 1994; Kelley et al., 2003]. In this work, we focus

\footnotetext{
${ }^{1}$ Eawag, Surface Waters-Research and Management, Kastanienbaum, Switzerland.

${ }^{2}$ Institute of Biogeochemistry and Pollutant Dynamics, ETH Zurich, Zurich, Switzerland.

${ }^{3}$ Department of Geology and Geophysics, Yale University, New Haven, Connecticut, USA.

${ }^{4}$ Rockland Scientific International Inc., Victoria, British Columbia Canada.

${ }^{5}$ Physics of Aquatic Systems Laboratory-Margaretha Kamprad Chair of Environmental Science and Limnology, ENAC, EPFL, Lausanne, Switzerland

Corresponding author: A. Wüest, Eawag, Surface Waters-Research and Management, Seestrasse 79, CH-6047 Kastanienbaum, Switzerland. (alfred.wueest@eawag.ch)

(C) 2013. American Geophysical Union. All Rights Reserved. 2169-9275/13/10.1002/2013JC009166
}

on the diffusive type of double-diffusion, where the faster diffusing agent (temperature $T$ in our case) is destabilizing and the slower diffusing agent (dissolved substances DS in our case) is stabilizing.

[3] Double-diffusive staircases are found in polar oceans [Neal et al., 1969; Foster and Carmack, 1976; Padman and Dillon, 1987], the Mediterranean and Black Seas [Özsoy and Besiktebe, 1995] and a variety of lakes of very different environments in Antarctica [Hoare, 1968], North America [Osborn, 1973], Europe [Sánchez and Roget, 2007; Boehrer et al., 2009], and Africa [Newman, 1976; Schmid et al., 2004, 2010; for a review see Wüest et al., 2012]. Double-diffusive heat fluxes are of particular interest in the Arctic Ocean, where they play a role in the heat exchange between a warm intrusion from the North Atlantic [Carmack et al., 1997] and the overlying sea ice [Timmermans et al., 2008; Turner, 2010].

[4] Flux estimates and theoretical models for double diffusion are usually based on laboratory experiments with rigid (and often unrealistic) boundary conditions. How well they apply in large and dynamic natural systems is still an open question, which we address with our measurements at Lake Kivu.

[5] The double-diffusive staircases in Lake Kivu consist of up to 300 steps (Figure 1), distributed almost over the entire water column between $110 \mathrm{~m}$ and the maximum depth of $485 \mathrm{~m}$ [Schmid et al., 2010]. With its manageable size, permanent stratification, small horizontal gradients, 

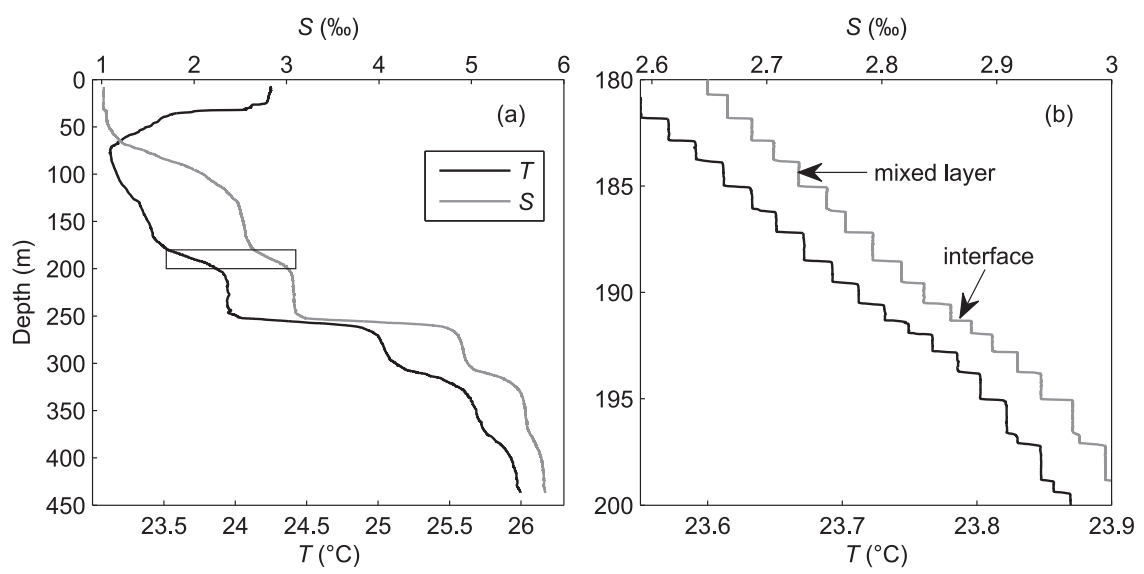

Figure 1. (a) Typical Lake Kivu profile of temperature and salinity $\left(1^{\circ} 47^{\prime} 28^{\prime \prime} \mathrm{S}, 29^{\circ} 13^{\prime} 30^{\prime \prime} \mathrm{E}, 2\right.$ February 2011). (b) Double-diffusive staircases within the $20 \mathrm{~m}$ long section marked by the rectangle in (a). Adapted from Sommer et al. [2013].

weak currents, weak Coriolis forcing, and slowly evolving water properties, Lake Kivu is an ideal study environment for double-diffusion [Schmid and Wüest, 2012] and represents an intermediate system between small-scale laboratory experiments and the ocean.

[6] We extend previous observational studies of double diffusion [Padman and Dillon, 1987; Sánchez and Roget, 2007; Timmermans et al., 2008; Schmid et al., 2010] by simultaneously measuring the microstructure of conductivity $C\left(\mu \mathrm{S} \mathrm{cm}^{-1}\right)$ in addition to $T$ that allows us to estimate also the density profiles. Our goal is to shed light on the density structure of the interfaces and to test existing flux laws by measuring molecular fluxes through interfaces. In particular, we address the question of whether interfaces have a double boundary-layer structure, and whether there is an associated critical boundary-layer Rayleigh number, as proposed by Linden and Shirtcliffe [1978] and Worster [2004]. Then, we test a basic assumption of many flux parameterizations, i.e., that the heat flux through doublediffusive staircases is independent of the mixed layer thickness [Turner, 1965]. Finally, we compare the Lake Kivu flux measurements to the often cited flux parameterization of Kelley [1990].

[7] The manuscript is structured as follows. In section 2, we introduce Lake Kivu, the vertical microstructure profiler, the evaluation algorithm, and our method for calculating water density. In section 3 , we summarize the theoretical background essential for this work. In section 4 , we present histograms of the measured staircase parameters and in section 5, we compare our data set to theoretical models and discuss the influence of our findings on heat flux estimates in the Arctic Ocean and Lake Kivu.

\section{Methods}

\subsection{Lake Kivu}

[8] Lake Kivu is located at the border between Rwanda and the Democratic Republic of the Congo (Figure 2). The surface area, the volume, and the maximum depth are 2370 $\mathrm{km}^{2}, 580 \mathrm{~km}^{3}$, and $485 \mathrm{~m}$, respectively [Descy et al., 2012]. Below $\sim 65 \mathrm{~m}$, the lake is permanently stratified. Water density is determined by four agents, which all increase with depth: salinity $\mathrm{S}(\%), T\left({ }^{\circ} \mathrm{C}\right)$, dissolved methane $\mathrm{CH}_{4}(\mathrm{~mol}$ $\left.\mathrm{L}^{-1}\right)$, and dissolved carbon dioxide $\mathrm{CO}_{2}\left(\mathrm{~mol} \mathrm{~L}^{-1}\right)$. While $T$ and $\mathrm{CH}_{4}$ gradients destabilize the water column, the permanent stratification is maintained by the gradients of $S$ and $\mathrm{CO}_{2}$ [Schmid et al., 2005; Pasche et al., 2009].

\subsection{Vertical Microstructure Profiler}

[9] During two field campaigns from 18 April 2010 to 2 May 2010 and 19 January 2011 to 4 February 2011, we

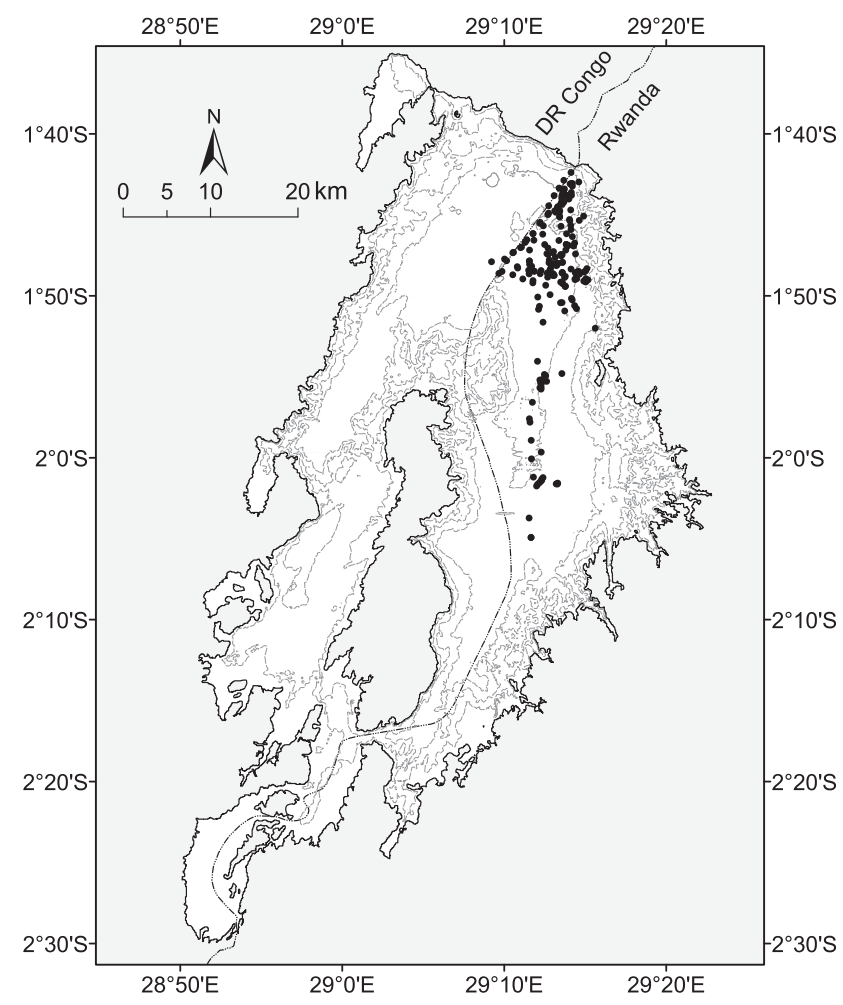

Figure 2. Profiling locations on Lake Kivu. Black dots indicate the 225 profiles collected in 2010 and 2011. Bathymetric lines denote $100 \mathrm{~m}$ depth intervals; the thick line corresponds to the lake surface. The dash-dotted line indicates the border between the neighboring countries. 
measured 225 profiles of $T$ and $C$ with a loosely tethered, free-falling vertical microstructure profiler (VMP) manufactured by Rockland Scientific International (RSI, Figure 3a) [Sommer et al., 2013]. The profiling length of the total data set is $\sim 55 \mathrm{~km}$. Three pairs of microstructure sensors were mounted at the nose of the instrument where they were exposed to the undisturbed natural water (Figures $3 \mathrm{~b}$ and $3 \mathrm{c}$ ). For this work, we exploit only the $T$ and $C$ signal of two fast FP07 (MicT, RSI, Canada and GE, USA) thermistors, and two fast SBE-7 (MicC, Sea-Bird, USA) conductivity micro-sensors, sampled at $512 \mathrm{~Hz}$. Responses and noise levels of the sensors have been studied in detail by Sommer et al. [2013]. They concluded that the time response of the MicT has a half-power frequency of 10.2 $\mathrm{Hz}$ and a root mean square noise level of $1.2 \times 10^{-5} \mathrm{~K}$. The half-power frequency of the $\mathrm{MicC}$ is $47 \mathrm{~Hz}$ and in addition to the time response, a spatial response must be accounted for with a half-power wave number of 240 cycles $/ \mathrm{m}$. The two MicC sensors have noise levels of $0.12 \mu \mathrm{S} \mathrm{cm}^{-1}$ and $0.06 \mu \mathrm{S} \mathrm{cm}^{-1}$, respectively. The profiling speeds were: $0.19 \mathrm{~m} \mathrm{~s}^{-1}$ (for $21 \%$ of the measured interfaces), $0.38 \mathrm{~m} \mathrm{~s}^{-1}$ (58\%), and $0.90 \mathrm{~m} \mathrm{~s}^{-1}(21 \%)$. We include data measured at all three speeds for analysis, since speed has only a minor influence on the spatial resolution, if the frequency responses of the microstructure sensors are correctly accounted for [Sommer et al., 2013].

\subsection{Evaluation Algorithm}

[10] The important staircase parameters for this study are the interface thicknesses $h_{T}(\mathrm{~m})$ and $h_{C}(\mathrm{~m})$ the step sizes across interfaces $\Delta T(\mathrm{~K})$ and $\Delta C\left(\mu \mathrm{S} \mathrm{cm}^{-1}\right)$, and the mixed layer thicknesses $H_{T}(\mathrm{~m})$ and $H_{C}(\mathrm{~m})$ (Figure 4). The ratios $\Delta T / h_{T}$ and $\Delta C / h_{C}$ represent the interfacial gradients and are used to calculate molecular fluxes through interfaces; $H_{T}$ is needed for estimating the Rayleigh number. The interface thicknesses of $T$ and $C$ are defined by
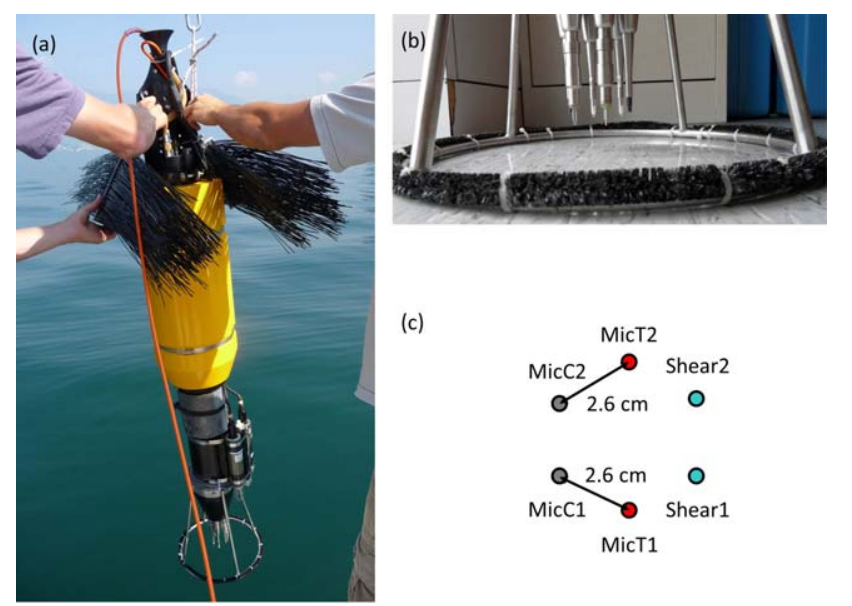

(c)

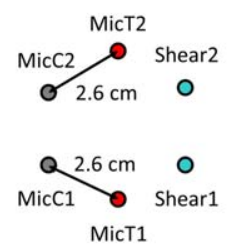

Figure 3. (a) Vertical microstructure profiler (VMP). (b) Six microstructure sensors mounted at the instrument nose and protected by a metal frame covered by black brushes. (c) Microstructure sensor arrangement when facing the instrument nose (for abbreviations, see text). Adapted from Sommer et al. [2013].

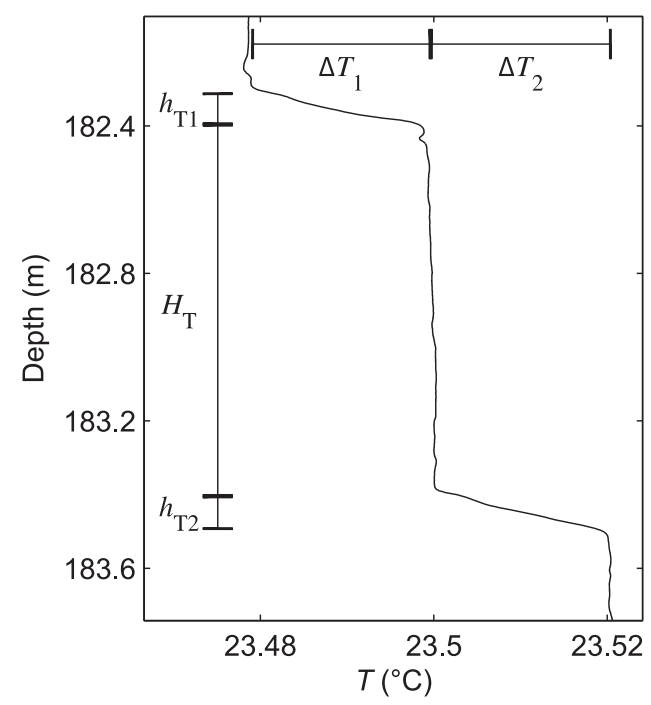

Figure 4. Illustration of the staircase parameters $h_{T}$ (interface thickness), $H_{T}$ (mixed layer thickness) and $\Delta T$ (step size) based on two measured temperature interfaces separated by a mixed layer $\left(1^{\circ} 44^{\prime} 31^{\prime \prime} \mathrm{S}, 29^{\circ} 13^{\prime} 18^{\prime \prime} \mathrm{E}, 3\right.$ February 2011). The same notation holds for $C, S, \mathrm{CO}_{2}, \mathrm{CH}_{4}$, $\rho_{T}$, and $\rho_{\mathrm{DS}}$.

$$
h_{T}=\Delta T(\mathrm{~d} T / \mathrm{d} z)^{-1}
$$

and

$$
h_{C}=\Delta C(\mathrm{~d} C / \mathrm{d} z)^{-1}
$$

where $z$ is depth ( $m$, positive downward) and gradients are determined at the depth of the interface center [Sommer et al., 2013].

[11] In order to manage our enormous data set, we developed an interface detection algorithm to extract the staircase parameters from measured $T$ and $C$ profiles. The algorithm is described in detail in Sommer et al. [2013] and is based on four criteria:

[12] (i) The interfacial gradient is large compared to the background gradient.

[13] (ii) The gradients in the two adjacent mixed layers are small compared to the background gradient.

[14] (iii) All four microstructure sensors (two MicT and two MicC) detect the same interface based on arguments (i) and (ii).

[15] (iv) Profiles of $T$ and $C$ are close to linear in their interface core.

[16] In total, 9401 interfaces passed all four criteria and form the basis for this work.

[17] Measured interface thicknesses are always larger than their real values because of the smoothing effect of the sensor responses. Sommer et al. [2013] estimated the MicT and MicC sensor responses and developed a method to correct each measured interface thickness to obtain its true value. Here we use this corrected data set for further analysis.

\subsection{Density Steps}

[18] Having evaluated the $T$ and $C$ profiles, we now present our method to deduce the corresponding information 
for $S$, DS, and density. In most studies of double diffusion, density is defined by two agents only that diffuse at different rates. Those two agents are typically $T$ and $S$, corresponding to the oceanic case [Linden and Shirtcliffe, 1978; Newell, 1984; Timmermans et al., 2007], or sugar and salt in laboratory experiments [Shirtcliffe, 1973; Stamp et al., 1998]. In Lake Kivu, four agents contribute to density: $T$, $S, \mathrm{CO}_{2}$, and $\mathrm{CH}_{4}$ [Schmid et al., 2005]. The fastest diffusing agent is $T$ (molecular diffusivity $\kappa_{T}=1.4 \times 10^{-7} \mathrm{~m}^{2}$ $\left.\mathrm{s}^{-1}\right)$, whereas the molecular diffusivities of $S\left(1.2 \times 10^{-9}\right.$ $\left.\mathrm{m}^{2} \mathrm{~s}^{-1}\right), \mathrm{CO}_{2}\left(1.9 \times 10^{-9} \mathrm{~m}^{2} \mathrm{~s}^{-1}\right)$, and $\mathrm{CH}_{4}\left(1.8 \times 10^{-9}\right.$ $\mathrm{m}^{2} \mathrm{~s}^{-1}$ ) (at the in situ $T$ of $\sim 25^{\circ} \mathrm{C}$ ) [Lide, 2011] are similar and approximately one hundred times smaller than the molecular diffusivity of $T$. We thus group the $S, \mathrm{CO}_{2}$, and $\mathrm{CH}_{4}$ together to form the slower diffusing agent DS. The diffusivity of $S$ is approximated by the weighted average of the most abundant Lake Kivu salts, which have molecular diffusivities in the range of $(0.71-1.96) \times 10^{-9} \mathrm{~m}^{2} \mathrm{~s}^{-1}$ [Yuan-Hui and Gregory, 1974]. The "artificial" molecular diffusivity $\kappa_{\mathrm{DS}}=1.43 \times 10^{-9} \mathrm{~m}^{2} \mathrm{~s}^{-1}$, which we use from now on for DS, is the average of the diffusivities of $S$, $\mathrm{CO}_{2}$, and $\mathrm{CH}_{4}$, weighted by their individual contribution to the density gradient, which is $\sim 79 \%, 32 \%$, and $-11 \%$, respectively [Schmid et al., 2004]. Including the destabilizing $\mathrm{CH}_{4}$ into the stabilizing component DS is not of concern based on the experimental findings of Griffiths [1979].

[19] As DS is a mixture of components that have slightly different molecular diffusivities, each individual component might contribute to the interfacial density structure and thus the dynamics of the double-diffusive layering. However, experiments by Griffiths [1979] showed, that this effect is minor for $2<R_{\rho}<4$, which contains $51 \%$ of our data. Here, the density ratio $R_{\rho}=\Delta \rho_{\mathrm{DS}} / \Delta \rho_{T}$ is the ratio of the fractional density steps of DS and $T$ across an interface. Because the dynamics of multicomponent convection are still not well understood [Turner, 1985], we treat DS as a single component with molecular diffusivity $\kappa_{\mathrm{DS}}$.

[20] For studying the structure of double-diffusive interfaces, knowledge on the contributions of $T$ and DS to density is essential. This would require microstructure information on $T, S, \mathrm{CO}_{2}$, and $\mathrm{CH}_{4}$, of which only $T$ is obtained directly from our measurements. Having both $T$ and $C$ information, it is possible to calculate $S$ [Wüest et al., 1996]. For $\mathrm{CO}_{2}$ and $\mathrm{CH}_{4}$, we have only the largescale profiles [Schmid et al., 2005], which contain no information on the double-diffusive steps. We thus estimate the microstructure of $\mathrm{CO}_{2}$ and $\mathrm{CH}_{4}$ by making three assumptions: (i) The large-scale profiles of $\mathrm{CO}_{2}$ and $\mathrm{S}$ are related; (ii) the large-scale profiles of $\mathrm{CO}_{2}$ and $\mathrm{CH}_{4}$ profiles are proportional to each other; and (iii) assumptions (i) and (ii) are also valid for the microstructure of $\mathrm{CO}_{2}$ and $\mathrm{CH}_{4}$.

[21] Assumptions (i) and (ii) are based on observations of Schmid et al. [2005]. The large-scale structure of $\mathrm{CO}_{2}$ is well described as a function of $S$ by a second-order polynomial $\mathrm{CO}_{2}=p_{0}+p_{1} S+p_{2} S^{2}$ with $p_{0}=-0.0182 \mathrm{~mol} \mathrm{~L}^{-1}$, $p_{1}=0.0062 \mathrm{~mol} \mathrm{~L}^{-1} \%{ }^{-1}, p_{2}=0.0023 \mathrm{~mol} \mathrm{~L}^{-1} \%{ }^{-2}$, where the coefficients are obtained by a least-square fit of the background $S$ profile to the $\mathrm{CO}_{2}$ profile below a depth of $100 \mathrm{~m}\left(R^{2}>0.99\right)$. The $\mathrm{CO}_{2}$ profile agrees with the fit within $10 \%$ in the staircase region. Furthermore, a constant gas ratio of

$$
\gamma_{g}=\left[\mathrm{CO}_{2}\right] /\left[\mathrm{CH}_{4}\right]=4.8
$$

was shown to agree well with direct $\mathrm{CH}_{4}$ measurements below $100 \mathrm{~m}$ depth [Schmid et al., 2005]. Assumption (iii) is acceptable because $\mathrm{S}, \mathrm{CO}_{2}$, and $\mathrm{CH}_{4}$ diffuse at similar rates and convective mixing in the homogeneous layers affects all three DS ingredients approximately in the same way.

[22] In equations (1a) and (1b), we defined interface thicknesses for $T$ and $C$. The same definitions hold for $S$, $\mathrm{CO}_{2}, \mathrm{CH}_{4}$, and as well for their density contributions $\rho_{T}$, $\rho_{S}, \rho_{\mathrm{CO} 2}, \rho_{\mathrm{CH} 4}$, and $\rho_{\mathrm{DS}}$. The parameters $\Delta T, h_{T}, \Delta C$, and $h_{C}$ are directly extracted from the measurements. Step sizes and interface thicknesses of the other agents are derived from the $T$ and $C$ parameters as described below.

[23] The salinity step size $\Delta S$ is calculated from the mixed layer $C$ and $T$ using a typical ionic composition for Lake Kivu water and following the methodology of Wüest et al. [1996]; $\Delta \mathrm{CO}_{2}=\left(p_{1}+2 p_{2} S_{\text {int }}\right) \Delta S$, where $S_{\text {int }}$ is the salinity at the depth of the interface; $\Delta \mathrm{CH}_{4}=\Delta \mathrm{CO}_{2} / \gamma_{g}$; $\Delta \rho_{T}=\rho_{0} \alpha \Delta T$, where $\rho_{0}=1000.6 \mathrm{~kg} \mathrm{~m}^{-3}$ is the average water density below $100 \mathrm{~m}$ depth and $\alpha=(2.43-2.78) \times$ $10^{-4} \mathrm{~K}^{-1}$ [Chen and Millero, 1986] is the T-dependent thermal expansion coefficient; $\Delta \mathrm{DS}$ is not defined because DS consists of three different agents; $\Delta \rho_{\mathrm{S}}=\rho_{0} \beta_{S} \Delta S$, where $\beta_{S}=(7.50-7.55) \times 10^{-4} \mathrm{~kg} \mathrm{~g}^{-1}$ [Chen and Millero, 1986] is the haline contraction coefficient, $\Delta \rho_{\mathrm{CO} 2}=\rho_{0} \beta_{\mathrm{CO} 2} \Delta \mathrm{CO}_{2}$ and $\Delta \rho_{\mathrm{CH} 4}=\rho_{0} \beta_{\mathrm{CH} 4} \Delta \mathrm{CH}_{4}$, where $\beta_{\mathrm{CO} 2}\left(0.0125 \mathrm{~L} \mathrm{~mol}^{-1}\right)$ and $\beta_{\mathrm{CH} 4}\left(-0.020 \mathrm{~L} \mathrm{~mol}^{-1}\right)$ are the contraction coefficients of $\mathrm{CO}_{2}$ and $\mathrm{CH}_{4}$, taken as constants over this small $T$ range. Finally, $\Delta \rho_{\mathrm{DS}}=\Delta \rho_{S}+\Delta \rho_{\mathrm{CO} 2}+\Delta \rho_{\mathrm{CH} 4}$.

[24] Interface thickness: For the $S$ interface thickness $h_{S}=\Delta S(\mathrm{~d} S / \mathrm{d} z)^{-1}$, we use $\Delta S$ as explained above and we determine the $S$ gradient by

$$
\frac{\mathrm{d} S}{\mathrm{~d} z}=\frac{\frac{\mathrm{d} C}{\mathrm{~d} z}-\left.\frac{\partial C}{\partial T}\right|_{S} \frac{\mathrm{d} T}{\mathrm{~d} z}}{\left.\frac{\partial C}{\partial S}\right|_{T}}
$$

[25] Here, per definition $\mathrm{d} C / \mathrm{d} z=\Delta C / h_{C}$ and $\mathrm{d} T / \mathrm{d} z=\Delta T /$ $h_{T}$ and the subscripts of the gradients indicate the parameter which is kept constant. From equations (1) and (2) and assuming that $\mathrm{CO}_{2}$ is proportional to $S$ for small changes of $S$ (such as $\Delta S$ ), we get $h_{S}=h_{\mathrm{CO} 2}=h_{\mathrm{CH} 4}=h_{\mathrm{DS}}$. Assuming a linear approximation of the equation of state we further get $h_{T}=h_{\rho, T}$ and $h_{\mathrm{DS}}=h_{\rho, \mathrm{DS}}$.

\section{Theoretical Background}

[26] Predicting vertical fluxes through double-diffusive staircases has been the focus of many laboratory studies in the past [Turner, 1965, 1973; Marmorino and Caldwell, 1976; Newell, 1984; Fernando, 1989; Kelley, 1990]. One of the goals was always to estimate fluxes based on easily measurable parameters, such as step sizes or mixed layer thicknesses. For that purpose, the heat flux $F_{H}\left(\mathrm{~W} \mathrm{~m}^{-2}\right)$ is usually parameterized directly and the salt flux is expressed as a function of the density flux ratio $R_{F}(-)$ and $F_{H}$. In our case, salt is replaced by DS and the flux of DS is expressed in density units. The density flux ratio $R_{F}$ is thus defined as 


$$
R_{F}=\frac{F_{\rho, D S}}{\left(\alpha / c_{p}\right) F_{H}}
$$

with $c_{p}\left(\mathrm{~J} \mathrm{~kg}^{-1} \mathrm{~K}^{-1}\right)$ being the specific heat capacity of water. Laboratory experiments showed that $F_{H}$ as well as $R_{F}$ both strongly increase when $R_{\rho}$ becomes small, whereas for large $R_{\rho}$ the dependence on $R_{\rho}$ is weak. The most commonly used parameterization for $F_{H}$ and $R_{F}$ was introduced by $\mathrm{Kel}$ ley [1990], who used the scaling relation of Turner [1965] and an empirical fit to various laboratory data sets. In order to predict $F_{H}$ and $R_{F}$ for certain ranges of $R_{\rho}$, a number of models [Linden and Shirtcliffe, 1978; Newell, 1984; Fernando, 1989; Stamp et al., 1998] have been developed. We focus on the model by Linden and Shirtcliffe [1978] because it is valid for the intermediate $R_{\rho}$ usually observed in natural waters and it assumes a double-boundary-layer structure of the interface that can be directly tested by our measurements.

[27] We first point out some interesting aspects of the boundary-layer theory of Linden and Shirtcliffe [1978]. Then we introduce the "4/3 law" of Turner [1965] that is the basis of many theoretical models [Marmorino and Caldwell, 1976; Linden and Shirtcliffe, 1978; Kelley, 1990; Worster, 2004] and finally, we focus on the parameterization by Kelley [1990] that is often applied to calculate double-diffusive fluxes in oceans and lakes [Schmid et al., 2004, 2010; Sánchez and Roget, 2007; Polyakov et al., 2012]. For each theory, we briefly mention which aspect we will test using the Lake Kivu data set.

\subsection{Boundary-Layer Model by Linden and Shirtcliffe [1978]}

[28] The model of Linden and Shirtcliffe [1978] is valid in the range of $1<R_{\rho}<\left(\kappa_{S} / \kappa_{T}\right)^{-1 / 2}=\tau^{-1 / 2} \approx 10$ and agrees with experimental data for $2<R_{\rho}<7$ within a factor of two. The model assumes steady state and a double-boundarylayer structure of the interface. Within the diffusive core of the interface the gradients of $T$ and $S$ are constant and heat and salt are transported by molecular diffusion. Outside this core, marginally unstable boundary layers develop which are characterized by a boundary-layer Rayleigh number $\mathrm{Ra}_{\mathrm{bl}}(-)$. When a critical boundary-layer Rayleigh number $\mathrm{Ra}_{\mathrm{bl}, \mathrm{cr}}(-)$ is exceeded, the boundary layers are assumed to break off into the mixed layer. The steady state assumption requires that the molecular transport through the core is balanced by the advective flux of heat and salt into the mixed layers. This leads to a constant density flux ratio

$$
R_{F, \mathrm{LS}}=\tau^{1 / 2} \approx 0.1
$$

[29] The sole adjustable parameter of this model is the critical boundary-layer Rayleigh number $\mathrm{Ra}_{\mathrm{bl}, \mathrm{cr}}$. Linden and Shirtcliffe [1978] took $\mathrm{Ra}_{\mathrm{bl}, \mathrm{cr}}=1629$ in line with Howard's [1964] model for high Rayleigh number thermal convection. Worster [2004] derived $\mathrm{Ra}_{\mathrm{bl}, \mathrm{cr}}$ by matching an extended model of Linden and Shirtcliffe [1978] to the experimental data of Turner [1965] and determined $\mathrm{Ra}_{\mathrm{bl}, \mathrm{cr}}=8801$ for a heat-salt system $(\tau \approx 0.01)$. Interestingly, for a sugar-salt system $(\tau \approx 0.3)$, he found $\mathrm{Ra}_{\mathrm{bl}, \mathrm{cr}}=738$, suggesting $\mathrm{Ra}_{\mathrm{bl}, \mathrm{cr}}$ is a function of $\tau$.

[30] In previous field studies, the stabilizing component (DS) was ignored and $\mathrm{Ra}_{\mathrm{bl}}$ was only calculated based on the destabilizing agent $(T)$ because instrumentation did not allow for resolution of the interface structure of the stabilizing agent [Padman and Dillon, 1989; Sánchez and Roget, 2007]. We calculate $\mathrm{Ra}_{\mathrm{bl}}$ based on the density structure of the interface that is derived from both $T$ and DS. We expect the histogram of $\mathrm{Ra}_{\mathrm{bl}}$ to cut off at $\mathrm{Ra}_{\mathrm{bl}, \mathrm{cr}}$, if the theory of Linden and Shirtcliffe [1978] is appropriate.

[31] We briefly introduce the definition of $\mathrm{Ra}_{\mathrm{bl}}$ by Linden and Shirtcliffe [1978] with the notation of Carpenter et al. [2012a, 2012b] which is used here. We define $\mathrm{Ra}_{\mathrm{bl}}$ for an individual interface as the average $\mathrm{Ra}_{\mathrm{bl}}$ of the upper and the lower boundary layer. For the lower boundary layer

$$
\mathrm{Ra}_{b l} \equiv \frac{g \delta \rho b^{3}}{\rho_{0} v \kappa_{T}}
$$

where $g\left(\mathrm{~m} \mathrm{~s}^{-2}\right)$ is the gravitational acceleration, $b \equiv$ $\left(h_{T}-h_{\mathrm{DS}}\right) / 2(\mathrm{~m})$ is a representative thickness of the boundary layer, and $\delta \rho\left(\mathrm{kg} \mathrm{m}^{-3}\right)$ is a representative boundarylayer density scale defined by

$$
\delta \rho b \equiv \int_{z_{b l}}^{z_{H, T / 2}}\left|\rho(z)-\rho_{m l}\right| d z
$$

[32] Here $\rho_{\mathrm{ml}}\left(\mathrm{kg} \mathrm{m}^{-3}\right)$ is the average density of the lower mixed layer (determined over the mid $50 \%$ of the mixed layer), $z_{\mathrm{bl}}(\mathrm{m})$ is the closest $z$ below the interface center which fulfills $\left|\rho(z)-\rho_{\mathrm{ml}}\right|=0$ and $z_{H, T / 2}(\mathrm{~m})$ is the center of the lower mixed layer adjacent to the interface. In Figure 5a, $\delta \rho b$ corresponds to the gray area. In practice, we assume an error function profile of $T$ and $S$ with the same $h_{T}, h_{\mathrm{DS}}, \Delta \rho_{T}$, $\Delta \rho_{\mathrm{DS}}$ as measured. This allows us to write $\mathrm{Ra}_{\mathrm{bl}}$ as a function of $R_{\rho}, r=h_{T} / h_{S}, \Delta \rho_{T}, h_{T}, \kappa_{T}, v, \rho, g$, and $H_{T}$ [see Carpenter et al. 2012b, for details], which are all available for Lake Kivu. For the upper boundary layer, $\mathrm{Ra}_{\mathrm{bl}}$ is calculated identically. Because we assume symmetry of the upper and lower boundary layer, the only difference between the two $\mathrm{Ra}_{\mathrm{bl}}$ is caused by the dependence on $H_{T}$. This dependence on $H_{T}$ is small as long as $H_{T} / h_{T}>5$ [Carpenter et al., 2012b].

\subsection{The $4 / 3$ Law by Turner [1965]}

[33] Turner [1965] used laboratory experiments to investigate an $S$ interface which was heated from below. The relevant physical parameters of the system are assumed to be $g \alpha \Delta T, \quad g \beta_{S} \Delta S, \kappa_{T}, \kappa_{S}, \quad v$, and the layer thickness $H=H_{T}+h_{T}$. Out of these four dimensionless control parameters can be formed. They are

$$
\mathrm{Ra}=\frac{g \alpha \Delta T H^{3}}{v \kappa_{T}}, R_{\rho}=\frac{g \beta_{S} \Delta S}{g \alpha \Delta T}=\frac{\Delta \rho_{S}}{\Delta \rho_{T}}, \tau=\frac{\kappa_{S}}{\kappa_{T}}, \operatorname{Pr}=\frac{v}{\kappa_{T}}
$$

corresponding to Rayleigh number, density ratio, diffusivity ratio, and Prandtl number, respectively. One important key system response is the dimensionless heat flux described by the Nusselt number $\mathrm{Nu}=\frac{F_{H}}{c_{p} \rho_{0} \kappa_{T} \Delta T / H}(-)$ where $F_{H}\left(\mathrm{~W} \mathrm{~m}^{-2}\right)$ is the total vertical heat flux across the interface. For constant $\tau$ and $\mathrm{Pr}, \mathrm{Nu}$ is expected only to depend on $\mathrm{Ra}$ and $R_{\rho}$. Turner [1965] suggested the functional form

$$
\mathrm{Nu}=C\left(R_{\rho}\right) \mathrm{Ra}^{\eta}
$$

with $\eta=1 / 3$, which removes the dependence on $H$. The $R_{\rho}$ dependent proportionality factor $C\left(R_{\rho}\right)(-)$ must be 

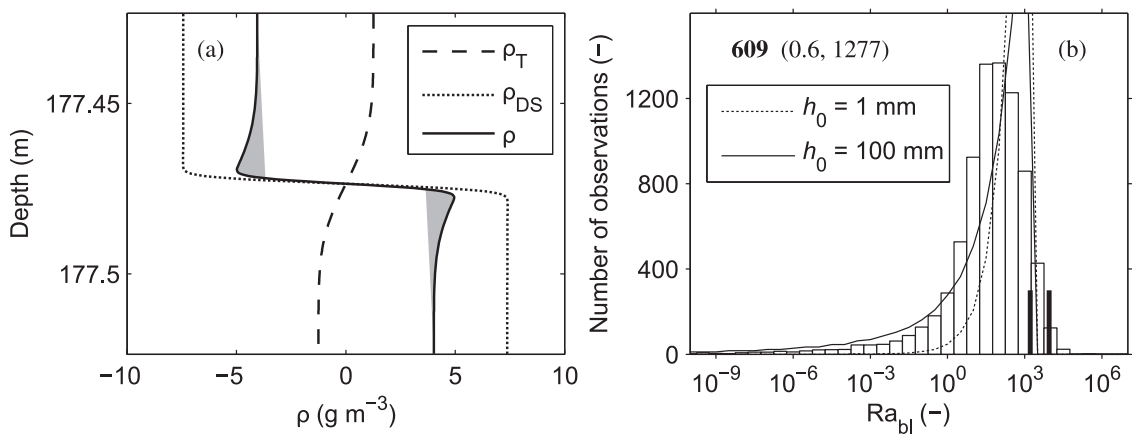

Figure 5. (a) Density contributions of temperature $\rho_{T}$ and dissolved substances $\rho_{\text {DS }}$ to the total density $\rho$. The $\rho_{T}$ and $\rho_{\text {DS }}$ profiles are represented by error functions, but interface thicknesses and step sizes are based on a measured interface $\left(1^{\circ} 47^{\prime} 0^{\prime \prime} \mathrm{S}, 29^{\circ} 13^{\prime} 18^{\prime \prime} \mathrm{E}, 21\right.$ January 2011$)$. The boundary layers next to the interface are indicated in gray. (b) Histogram of the boundary-layer Rayleigh numbers calculated from the Lake Kivu data set (arithmetic mean (bold) and 10th and 90th percentiles in parentheses). The thick vertical lines indicate the critical boundary-layer numbers $R a_{b l, c r}=1629$ and $R a_{b l, c r}=8801$ suggested by Linden and Shirtcliffe [1978] and Worster [2004], respectively. The two thin lines refer to simulated $\mathrm{Ra}_{\mathrm{bl}}$ histograms with initial interface thickness $h_{T}=h_{\mathrm{DS}}=h_{0}$. Other simulation parameters are fixed to average Lake Kivu values, i.e., $\Delta T=11 \mathrm{mK}, R_{\rho}=4, H_{T}=0.7 \mathrm{~m}$.

determined experimentally. Solving equation (9) for $F_{H}$, we get

$$
F_{H}=C\left(R_{\rho}\right) c_{p} \rho_{0}\left(\frac{\kappa_{T}^{2} g \alpha}{v}\right)^{1 / 3} \Delta T^{4 / 3}
$$

This law is often called the " $4 / 3$ law" due to the exponent on $\Delta T$.

[34] We will estimate the exponent $\eta$ in equation (9) by subdividing our data set into bins of $R_{\rho}$, so that $C$ becomes approximately constant. $\mathrm{Nu}$ and $\mathrm{Ra}$ will be calculated directly from our measurements assuming molecular transport through interfaces. The slope of a linear fit through the data (on a double-logarithmic scale) then determines $\eta$. For calculating Ra, we use $H=\overline{H_{T}}+h_{T}$, where $\overline{H_{T}}$ is the mean thickness of the mixed layers above and below the interface.

\subsection{Parameterization by Kelley [1990]}

[35] Kelley [1990] questioned the exponent $\eta=1 / 3$ of equation (9) based on a model for thermal convection that leads to $\eta=0.27 \pm 0.02$ which lies between $\eta=2 / 7$ [Castaing et al., 1989; Kerr, 1996; Sommeria, 1999] and $\eta=1 /$ $4\left(\mathrm{Ra}<10^{11}, \mathrm{Pr} \approx 7\right)$ [Grossmann and Lohse, 2000] of previous scaling laws for single-component convection. For double-diffusive convection, however, Kelley [1990] recommended to retain $\eta=1 / 3$ as long as observations do not provide evidence for a different exponent. Assuming $\eta=1 / 3$, he introduced an improved fit function to $C_{\text {Kel }}\left(R_{\rho}\right)=\mathrm{NuRa}^{-\eta}$ by compiling numerous available laboratory data sets and found

$$
C_{\text {Kel }}\left(R_{\rho}\right)=0.0032 \exp \left(\frac{4.8}{R_{\rho}^{0.72}}\right)
$$

[36] The density flux ratio $R_{F}$ as a function of $R_{\rho}$ was obtained from an empirical fit to the same experimental data used for $C_{\mathrm{Kel}}\left(R_{\rho}\right)$. The form of the fit function was based on the theory of Linden [1974] assuming that the total flux across the interface is a composition of a "diffusive flux" and an "entrainment flux" relevant for large and small $R_{\rho}$, respectively. Kelley [1990] then optimized the numerical values of the proposed form and got

$$
R_{F, \text { Kel }}\left(R_{\rho}\right)=\frac{R_{\rho}+1.4\left(R_{\rho}-1\right)^{3 / 2}}{1+14\left(R_{\rho}-1\right)^{3 / 2}}
$$

[37] Both equations (11) and (12) increase strongly when $R_{\rho} \rightarrow 1$ reflecting the increasing influence of advection across the interface when the stability of the interface decreases.

[38] Equations (11) and (12) will be compared to our Lake Kivu observations by assuming that the total fluxes are well represented by molecular fluxes through the interfaces. The molecular fluxes of heat $F_{H \text {,mol }}\left(\mathrm{W} \mathrm{m}^{-2}\right)$ and the density fluxes of dissolved substances $F_{\rho \text {,DS,mol }}\left(\mathrm{kg} \mathrm{m}^{-2}\right.$ $\mathrm{s}^{-1}$ ) through interfaces are defined by

$$
\begin{gathered}
F_{H, \mathrm{~mol}}=c_{p} \rho_{0} \kappa_{T} \Delta T h_{T}{ }^{-1} \\
F_{\rho, \mathrm{DS}, \mathrm{mol}}=\kappa_{\mathrm{DS}} \Delta \rho_{\mathrm{DS}} h_{\mathrm{DS}}{ }^{-1}
\end{gathered}
$$

where $c_{p}=(4168-4177) \mathrm{J} \mathrm{kg}^{-1} \mathrm{~K}^{-1}$ for Lake Kivu water. The molecular density flux ratio is then

$$
R_{F, \mathrm{~mol}}=\frac{F_{\rho, \mathrm{DS}, \mathrm{mol}}}{\left(\alpha / c_{p}\right) F_{H, \mathrm{~mol}}}=\tau r R_{\rho}
$$

with $\tau=\kappa_{\mathrm{DS}} / \kappa_{T} \approx 0.01$. For constant $\tau, R_{F, \text { mol }}$ thus only depends on $r$ and $R_{\rho}$, which are both measured in Lake Kivu.

[39] It has been suggested that molecular fluxes might underestimate the total fluxes, in particular for low $R_{\rho}[$ Linden and Shirtcliffe, 1978; Newell, 1984]. We have tested this by comparing two-dimensional direct numerical simulations with the Lake Kivu measurements (T. Sommer et al., Representativeness of direct numerical simulations 
for double diffusion in natural systems, submitted to Geophysical Research Letters, 2013). For $R_{\rho} \geq 3, F_{H \text {,mol }}$ underestimates the total heat flux by less than $10 \%$ and $R_{F, \text { mol }}$ underestimates the density flux ratio by less than $27 \%$. We emphasize that condition $i v$ of the algorithm is important to achieve good agreement between the two estimates, in particular for small $R_{\rho}$.

[40] In summary, all theories described in this section contain properties that can be directly compared to our measurements. Specifically, the histogram of $\mathrm{Ra}_{\mathrm{bl}}$ will shed light on the existence of a critical $\mathrm{Ra}_{\mathrm{bl}, \mathrm{cr}}$ as assumed by Linden and Shirtcliffe [1978] and Worster [2004] and molecular fluxes through interfaces will serve to test the 4/3 law of Turner [1965] and will be compared to the semiempirical flux law of Kelley [1990].

\section{Results}

[41] In this section, we present histograms of staircase parameters measured in Lake Kivu between $111 \mathrm{~m}$ and 451 $\mathrm{m}$ depth. Most of the data (58\%) is from the gradients between $180 \mathrm{~m}$ and $200 \mathrm{~m}$ as well as $300 \mathrm{~m}$ and $330 \mathrm{~m}$ depth. Each histogram contains 9401 data points. Arithmetic means and 10th and 90th percentiles are indicated in the top left corner of the panels.

[42] Histograms for the following staircase parameters are presented: Step sizes across interfaces for $T$ and $S$, density ratios $R_{\rho}$, interface thicknesses $h_{T}$ and $h_{S}$, their ratio $r$, mixed layer thicknesses for temperature $H_{T}$, Rayleigh numbers $\mathrm{Ra}$, molecular fluxes of heat $\left(F_{H, \mathrm{~mol}}\right)$ and density fluxes of $\mathrm{DS}\left(F_{\rho, \mathrm{DS}, \mathrm{mol}}\right)$ through interfaces and finally density flux ratios $R_{F, \text { mol }}$.

\subsection{Step Size}

[43] Histograms of the step size $\Delta T$ and $\Delta S$ are shown in Figures $6 \mathrm{a}$ and $6 \mathrm{c}$. The arithmetic means are $11 \mathrm{mK}(3,20)$ and $0.013 \%(0.002,0.024)$. The step sizes $\Delta \mathrm{CO}_{2}$ and $\Delta \mathrm{CH}_{4}$ are numerically estimated as functions of $S$ and are not shown.

[44] The histogram of $R_{\rho}$ for Lake Kivu is shown in Figure $6 \mathrm{e}$. The average is $4.0(2.4,5.6)$ and thus the Lake Kivu staircases are within the usually observed range of $R_{\rho}$ between 1 and 10 [Kelley et al., 2003].

\subsection{Interface Thickness}

[45] Interface thicknesses $h_{T}$ and $h_{\mathrm{DS}}$ are on average 9.2 $\mathrm{cm}(2.5,16.5)$ and $6.4 \mathrm{~cm}(0.4,13.5)$, respectively (Figures $6 \mathrm{~b}$ and $6 \mathrm{~d})$. The minimum interface thicknesses for DS and $T$ are $h_{\mathrm{DS} \text {, min }} \approx 1 \mathrm{~mm}$ and $h_{T \text {, min }} \approx 1 \mathrm{~cm}$, emphasizing our excellent spatial resolution, in particular of the $S$ measurements. The time scale of diffusion of those smallest interfaces is $h_{\mathrm{DS}, \min }{ }^{2}\left(4 \pi \kappa_{\mathrm{DS}}\right)^{-1} \approx h_{T, \text { min }}{ }^{2}\left(4 \pi \kappa_{T}\right)^{-1} \approx 1 \mathrm{~min}$. Such a short time scale proves the existence of active processes which effectively maintain interfaces. In Figure $6 \mathrm{~d}$, we observe a gap between the frequency of the thin interfaces (thicknesses $\sim 3 \mathrm{~mm}$, for an example see Figure 7a) and the thick interfaces $(\sim 6 \mathrm{~cm}$, see Figure $7 \mathrm{c})$. Interfaces with thicknesses in between the two peaks are usually disturbed and often show small mixed segments within the interface (Figure $7 b$ ). Such interfaces are rejected by the algorithm resulting in the separation of the two peaks in Figure $6 \mathrm{~d}$. The small mixed segments within the interface could be a signature of interfacial waves as described by Stamp et al.
[1998]. We plan to investigate this phenomenon in more detail in a future publication (see above), where we compare the Lake Kivu observations to direct numerical simulations.

[46] The interface thickness ratio $r$ is an important parameter for computing density flux ratios (equation (14)) and for studying the interfacial boundary layer (section 3.1). The theoretical range of $r$ is between one and $\left(\kappa_{T} /\right.$ $\left.\kappa_{\mathrm{DS}}\right)^{1 / 2} \approx 10$. An interface thickness ratio smaller than one is unlikely, because in that case $h_{\mathrm{DS}}>h_{T}$, which would imply that the $T$ interface is eroded more effectively than the $S$ interface. An interface with $r=1$ might exist directly after an erosion event before $h_{T}$ and $h_{\mathrm{DS}}$ begin growing again by molecular diffusion. The upper limit $r=\left(\kappa_{T}\right)$ $\left.\kappa_{\mathrm{DS}}\right)^{1 / 2}$ is the long-term asymptotic value for the molecular diffusion of $T$ and DS interfaces.

[47] Figure $6 \mathrm{f}$ shows the histogram of $r$ for Lake Kivu. For the investigated interfaces, $r$ is on average $3.3(1.0,7.7)$ and thus within the theoretical range explained above. However, we also detect few interfaces with $r<1(12 \%)$ and $r>10(7 \%)$, which are the result of slightly nonlinear interfaces, of which an example is shown in Figure $7 \mathrm{c}$. Here, the DS interface (approximated by $C$ ) has a slight kink close to the interface center, which decreases the measured gradient in the interface and therefore increases the calculated interface thicknesses so that $h_{\mathrm{DS}}>h_{T}$ $(r=0.85)$.

\subsection{Mixed Layer Thickness and Rayleigh Number}

[48] Average mixed layer thicknesses $H_{T}$ and $H_{S}$ are $0.72 \mathrm{~m}(0.33,1.17)$ and $0.75 \mathrm{~m}(0.36,1.22)$, respectively, and we only show the histogram of $H_{T}$ in Figure $6 \mathrm{~g}$ because the differences between the two are marginal.

[49] The average Rayleigh number $\mathrm{Ra}$ is $2.4(0.1,5.2) \times$ $10^{8}$ and the corresponding histogram is shown in Figure $6 \mathrm{~h}$.

\subsection{Molecular Fluxes Through Interfaces}

[50] Arithmetic means of $F_{H, \text { mol }}$ (equation (13a)) and $F_{\mathrm{DS} \text {,mol }}$ (equation (13b)) for all measured interfaces are $0.10 \mathrm{~W} \mathrm{~m}^{-2}(0.02,0.21)$ and $0.89 \mu \mathrm{g} \mathrm{m}^{-2} \mathrm{~s}^{-1}(0.07,1.63)$, respectively, and the corresponding histograms are shown in Figures $8 \mathrm{a}$ and $8 \mathrm{~b}$. The distribution of $R_{F, \text { mol }}$ (equation (14)) is shown in Figure 8c and its arithmetic mean is 0.11 $(0.03,0.21)$.

[51] In 2004, the average molecular heat flux through interfaces was estimated to be $0.02 \mathrm{~W} \mathrm{~m}^{-2}$ [Schmid et al., 2010], a factor of five less than our estimate. This difference is mainly caused by the different profile evaluation methods. We distinguish between four major differences of the two methods that all result in smaller heat fluxes for the estimate of Schmid et al. [2010]. The approximate contribution to the total difference (factor 5) is given in parentheses. (i) Both methods imply different interface thickness definitions (factor 2). Schmid et al. [2010] determined the interface thickness by visually estimating the depth of the upper boundary of one mixed layer and the lower boundary of the adjacent mixed layer above and subtracting the two values, whereas our definition is based on the gradient at the interface center. (ii) The manual evaluation of Schmid et al. [2010] is more efficient in detecting interfaces with small $\Delta T$ (factor 1.4). (iii) Schmid et al. [2010] did not account for the sensor response (factor 1.1). (iv) No 

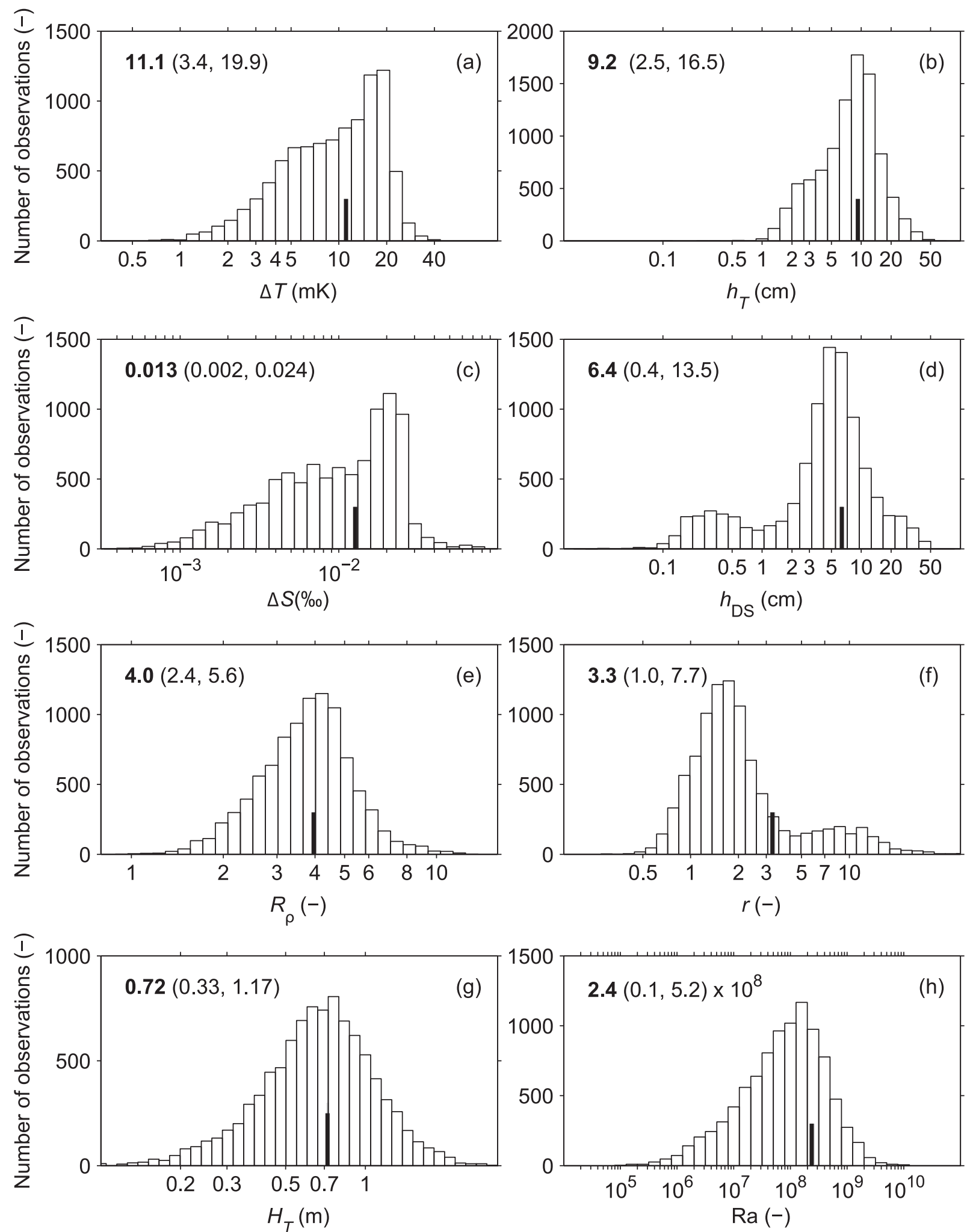

Figure 6. Histograms of (a and c) step sizes, (b and d) interface thicknesses, (e and $f$ ) their respective ratios, (g) temperature mixed layer thicknesses, and (h) Rayleigh numbers for all profiles over the entire depth range. Logarithmic scale is used for the $x$ axis. Arithmetic means are indicated by short vertical lines and bootstrapped 95\% confidence intervals of the mean are within the width of the lines. The numbers inside each panel indicate the arithmetic mean (bold) with the 10th and 90th percentiles in parentheses. Each histogram contains 9401 data points. 

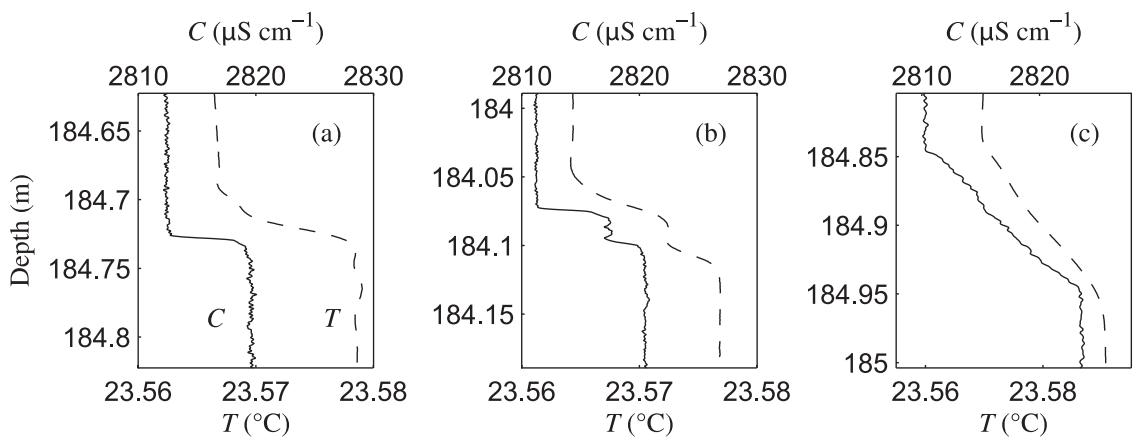

Figure 7. Example $T$ (dashed line) and $C$ (solid line) interfaces observed at $2<R_{\rho}<3$. (a) Extremely sharp $C$ interface. (b) Interface containing a mixed segment as expected for interfacial waves. Such interfaces are rejected by the algorithm. (c) Thick interface with $r=0.85$.

rejection criteria were used for disturbed interfaces (factor 1.2). The remaining factor of 1.4 might be caused by the temporal variation and the horizontal heterogeneity of the heat fluxes which we plan to investigate in a future publication.

\section{Discussion}

[52] Having outlined the relevant theories for this work in section 3, we now compare them to the Lake Kivu measurements. We present a histogram of $\mathrm{Ra}_{\mathrm{bl}}$ and compare it to the predictions of Linden and Shirtcliffe [1978] and Worster [2004]. We test the exponent $\eta$ in equation (9), which for $\eta=1 / 3$ results in the $4 / 3$ law and discuss the heat flux and density flux ratio parameterizations of Kelley [1990]. Finally, we estimate corrections for heat flux estimates in the Arctic Ocean.

\subsection{Critical Boundary-Layer Rayleigh Number}

[53] In the theories of Linden and Shirtcliffe [1978] and also Worster [2004], the boundary-layer water adjacent to the double-diffusive interface is assumed to be entrained into the mixed layer when a critical boundary-layer Rayleigh number $\mathrm{Ra}_{\mathrm{bl}, \mathrm{cr}}=1629$ or $\mathrm{Ra}_{\mathrm{bl}, \mathrm{cr}}=8801$ is exceeded, respectively. The histogram of $\mathrm{Ra}_{\mathrm{bl}}$ is shown in Figure $5 \mathrm{~b}$ with the average $\mathrm{Ra}_{\mathrm{bl}}$ being $609(0.6,1277)$. Most of the interfaces have $\mathrm{Ra}_{\mathrm{bl}} \approx 100$, which agrees well with the direct numerical simulations of Carpenter et al. [2012a]. The histogram of $\mathrm{Ra}_{\mathrm{bl}}$ does not show a sharp cut-off at a certain $\mathrm{Ra}_{\mathrm{bl}, \mathrm{cr}}$, but instead continuously decreases between $\mathrm{O}\left(10^{2}\right)$ and $\mathrm{O}\left(10^{4}\right)$. We provide three possible explanations for this smooth decrease. (i) Carpenter et al. [2012b] show that the instability of the boundary layers is time-dependent and thus linear stability theory with its prediction of $\mathrm{Ra}_{\mathrm{bl}, \mathrm{cr}}$ is not applicable to double-diffusive interfaces. (ii) The direct numerical simulations of Carpenter et al. [2012b] indicate that the boundary layers are rather swept away at variable time intervals by the mixed layer flow than being released from the interface after they have accumulated enough excess buoyancy. (iii) Measurement uncertainties in $\mathrm{Ra}_{\mathrm{bl}}$ (especially in parameter $b$ that enters equation (6) to the third power) might contribute to the smooth decrease of $\mathrm{Ra}_{\mathrm{bl}, \mathrm{cr}}$ at large $\mathrm{Ra}_{\mathrm{bl}}$.

[54] However, the models of Linden and Shirtcliffe [1978] and Worster [2004] only require an estimate for $\mathrm{Ra}_{\mathrm{bl} \text {,cr }}$ at which the boundary layers are released into the mixed layers, the reason for the break-off is not essential to the model. Both estimates of $\mathrm{Ra}_{\mathrm{bl}, \mathrm{cr}}=1629$ and 8801, respectively, are in the range of the observed drop-off in the histogram of $\mathrm{Ra}_{\mathrm{bl}}$ and are thus reasonable choices within the model limitations.

[55] The histogram of $\mathrm{Ra}_{\mathrm{bl}}$ in Figure $5 \mathrm{~b}$ has a long tail toward small $\mathrm{Ra}_{\mathrm{bl}}$, for which we now provide an explanation. For this purpose, we model the growth of $T$ and DS interface thicknesses by molecular diffusion from initially identical thicknesses. In the simulation, both interfaces are represented by error function profiles and have the initial thickness $h_{T}=h_{\mathrm{DS}}=h_{0}$. At equal time steps, $\mathrm{Ra}_{\mathrm{bl}}$ is calculated until a maximum $\mathrm{Ra}_{\mathrm{bl}, \mathrm{cr}}=10^{3}$ is reached. Our choice of $\mathrm{Ra}_{\mathrm{bl}, \mathrm{cr}}$ is arbitrary between $10^{2}$ and $10^{4}$. The histogram of the simulated $\mathrm{Ra}_{\mathrm{bl}}$ is then scaled to contain the same number of data points as the Lake Kivu data set. The results of two simulations with $h_{0}=1 \mathrm{~mm}$ and $h_{0}=100 \mathrm{~mm}$ are indicated by the two lines in Figure 5b. The simulation, in particular for $h_{0}=100 \mathrm{~mm}$, reproduces the tail toward small $\mathrm{Ra}_{\mathrm{bl}}$ and thus supports the idea of Linden and Shirtcliffe [1978] that the $T$ and DS interfaces periodically grow by molecular diffusion from initially the same thickness until they are released into the mixed layer at $\mathrm{Ra}_{\mathrm{bl}}$ between $10^{2}$ and $10^{4}$.

\subsection{Testing the $4 / 3$ Law}

[56] In section 3.1, we introduced the $4 / 3$ law as a basic assumption for heat flux parameterizations. The 4/3 law is based on $\mathrm{Nu} \sim \mathrm{Ra}^{\eta}$ with $\eta=1 / 3$. While for singlecomponent convection, $\eta$ has been widely studied and deviations from $1 / 3$ have been found, experiments are complex for double-diffusive convection, because $\mathrm{Nu}$ additionally depends on $R_{\rho}$ (equation (9)) and it is difficult keeping $R_{\rho}$ constant while varying $\mathrm{Ra}$.

[57] By assuming molecular fluxes through interfaces we estimate the exponent $\eta$ for double-diffusive convection. We use two independent estimates for $F_{H}$ in the definition of the Nusselt number: (i) $F_{H}=F_{H \text {,mol }}$ for $\mathrm{Nu}=\mathrm{Ra}^{\eta}$ and (ii) $F_{H}{ }^{*}=\left(c_{p} / \alpha\right) F_{\rho, \mathrm{DS}, \mathrm{mol}} R_{F, \mathrm{Kel}}{ }^{-1}$ for $\mathrm{Nu}^{*}=\mathrm{Ra}^{\eta^{*}}$. For the starred quantities, the heat flux is calculated from the density flux of dissolved substances and $R_{F, \text { Kel }}$, which only depends on $R_{\rho}$ (equation (12)). In order to estimate $\eta$ (and $\eta^{*}$ ), we first sort the Lake Kivu interfaces into bins of $R_{\rho}$ of interval 0.5 to ensure that $R_{\rho}$ (and therefore also $R_{F, \mathrm{Kel}}$ ) is approximately constant within each bin. We then estimate $\eta$ (and $\eta^{*}$ ) bin-wise from the slope of a least-square fit of 

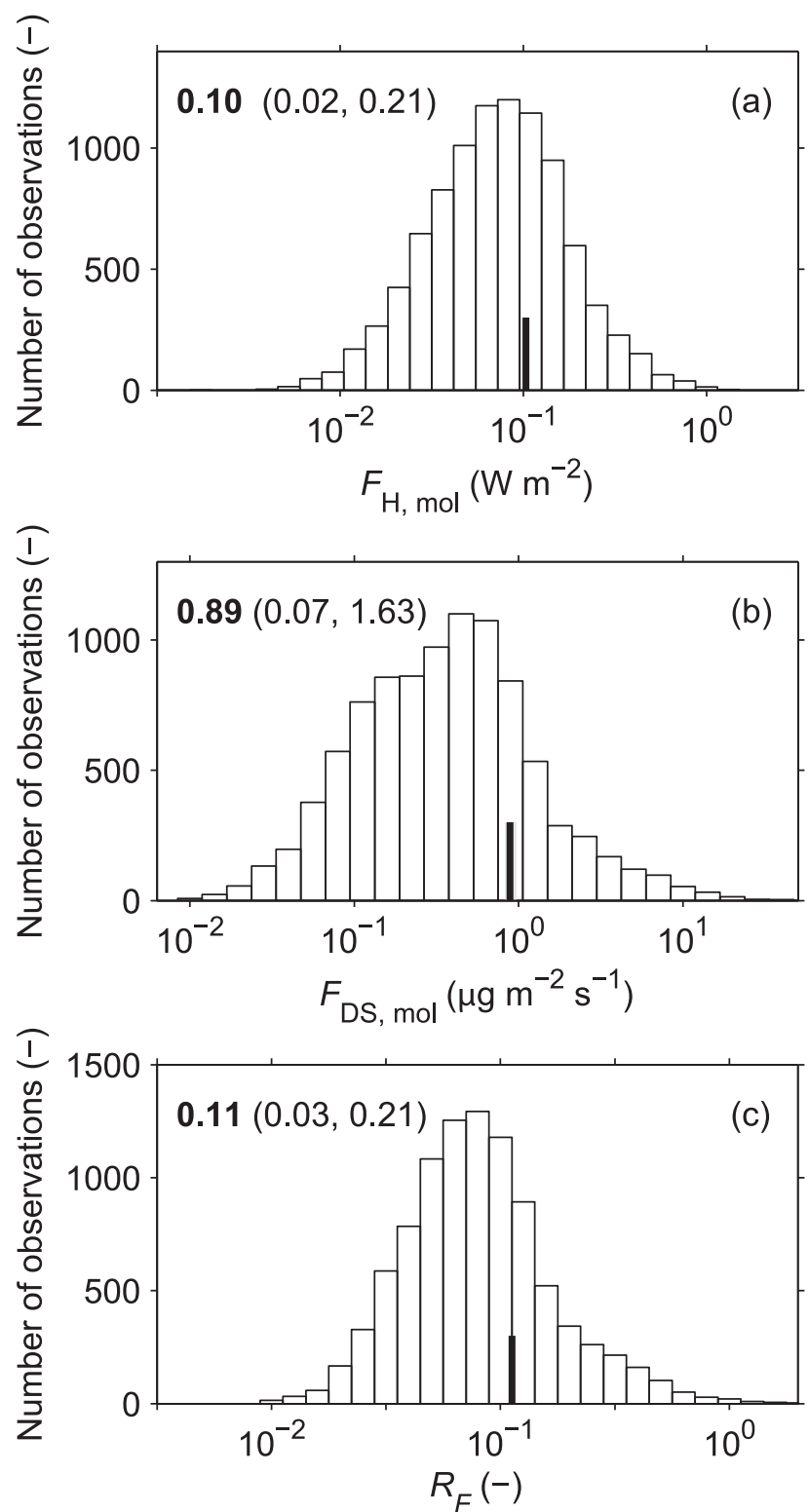

Figure 8. Histograms for (a) the molecular heat flux through interfaces, (b) the molecular density flux of dissolved substances through interfaces, and (c) the density flux ratio. Arithmetic means are indicated by short vertical lines and bootstrapped $95 \%$ confidence intervals of the mean are within the width of the lines. The numbers inside each panel indicate the arithmetic mean (bold) with the 10 th and 90th percentiles in parentheses.

$\mathrm{Nu}$ against $\mathrm{Ra}$ in double logarithmic space. Varying binsizes between 0.1 and 1.0 has only marginal effect on the estimates of $\eta$.

[58] In Figures 9a and 9c, we show fit examples (thick solid lines) for the bin $4<R_{\rho}<4.5$. The prediction of Kelley [1990] is indicated by the thin dashed line. In Figures $9 \mathrm{~b}$ and $9 \mathrm{~d}$, the fit slopes $\eta$ and $\eta^{*}$ are plotted together with their $95 \%$ bootstrapped confidence intervals as a function of $R_{\rho}$.

[59] We find that for the entire range of $R_{\rho}, \eta<1 / 3$. For $2<R_{\rho}<6, \eta=0.20 \pm 0.03$, where 0.20 is the average $\eta$ and 0.03 the average confidence interval in that range in Figure 9a. At large $R_{\rho}>7, \eta$ decreases and crosses zero at $R_{\rho} \approx 8$. Note that the two independent estimates $\eta$ and $\eta^{*}$ yield similar results, except at small $R_{\rho}<3$, where we expect disturbed interfaces, in particular for DS, because $\kappa_{\mathrm{DS}}<<\kappa_{T}$.

[60] We emphasize that linear fits of $y$ (here $\log _{10} \mathrm{Nu}$ ) on $x$ (here $\log _{10} \mathrm{Ra}$ ) assume that the entire uncertainty is in $y$, which is not the case here because both $\mathrm{Nu}$ and $\mathrm{Ra}$ are subject to measurement errors and natural fluctuations, with the latter being the dominant effect in Figure 9. Attributing uncertainties to $x$ can severely increase the slope of the fit. Following the methodology of Ricker [1973], we studied the sensitivity of the fit slope toward uncertainties in $x$ and found that our values of $\eta$ are unaffected by uncertainties in $x$ as long as the uncertainty in $y$ is at least twice as large as the uncertainty in $x$. Based on thermistor data (not yet published), we expect that the time scale of layer merging and splitting (causing changes in $\Delta T$ and $H$ and therefore in $\mathrm{Ra}$ ) is at least several days, whereas the time scale for interface diffusion (causing changes in $\mathrm{Nu}$ ) is several hours. Thus the uncertainty in $\mathrm{Nu}$ is much larger than the uncertainty in Ra and our result $\eta=0.20 \pm 0.03$ is unaffected.

[61] In section 3.3, we mentioned that $\eta<1 / 3$ has been found for single-component convection. We now show that $\eta \approx 0.2$ does not contradict previous double-diffusive experiments. In double-diffusive experiments, $C\left(R_{\rho}\right)=\mathrm{NuRa}^{-\eta}$ with $\eta=1 / 3$ is often plotted as a function of $R_{\rho}$ for intercomparison between different experiments and in order to obtain a continuous empirical fit function for $C\left(R_{\rho}\right)$ such as $\mathrm{C}_{\mathrm{Kel}}\left(R_{\rho}\right)$ (equation (11)). The observed scatter in $C\left(R_{\rho}\right)$ [e.g., Kelley et al., 2003, Figure 4] for fixed $R_{\rho}$ could be the result of systematic errors in $\eta$ in addition to random measurement errors and varying experimental boundary conditions. If we assume error-free experiments with identical boundary conditions and a true $\eta \neq 1 / 3$, then we can estimate the deviation $\Delta \eta=\eta-1 / 3$ that is needed to reproduce the same scatter as observed. We express the scatter in $C$ (at constant $R_{\rho}$ ) as

$$
\frac{C_{\mathrm{Ra} 1, \eta=1 / 3}}{C_{\mathrm{Ra} 2, \eta=1 / 3}}=\left(\frac{\mathrm{Ra}_{1}}{\mathrm{Ra}_{2}}\right)^{\Delta \eta} \equiv \xi
$$

where the left-hand side is the ratio of $C$ for two different Rayleigh numbers $\mathrm{Ra}_{1}$ and $\mathrm{Ra}_{2}$ and assuming that $\eta=1 / 3$ is the exponent that deviates from the true exponent by $\Delta \eta$. Note that measuring $\mathrm{Nu}$ and $\mathrm{Ra}$ over a larger range of $\mathrm{Ra}$ (at constant $R_{\rho}$ ) increases the confidence in the estimate of $\eta$. Kelley et al. [2003] estimated the scatter in $C$ to be $40 \%$ ( $\xi=1.4)$ and took $\mathrm{Ra}_{1} / \mathrm{Ra}_{2}=1 / 20$ based on experiments of Marmorino and Caldwell [1976], which yields $|\Delta \eta| \approx 0.11$. This is close to our estimate of $|\Delta \eta|=|0.2-1 / 3| \approx 0.13$. If our estimate was true, it would mean that most of the observed scatter in experiments is indeed caused by the choice of $\eta$ and the effects of measurement errors and boundary conditions are small. However, a scatter of $40 \%$ is a rather small estimate [Kelley et al., 2003, Figure 4] and the estimate of $\mathrm{Ra}_{1} / \mathrm{Ra}_{2}$ is uncertain, because the previous literature does not provide explicit values for this ratio at fixed $R_{\rho}$. Therefore, $|\Delta \eta|$ might be larger in reality. For example, taking $\mathrm{Ra}_{1} / \mathrm{Ra}_{2}=1 / 10$ and $\xi=2$ yields 

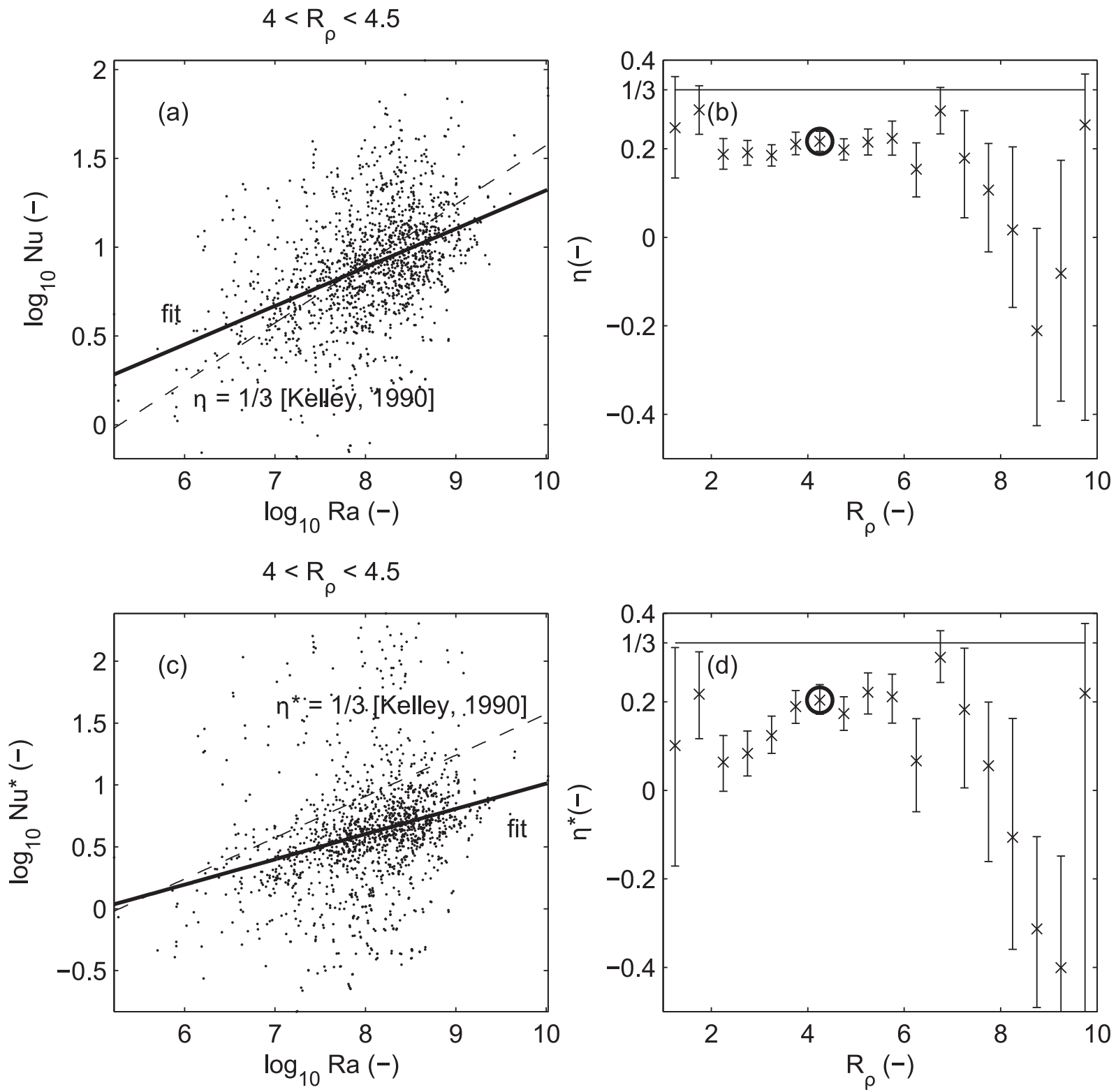

Figure 9. Dependence of the Nusselt number $\mathrm{Nu}$ on the Rayleigh number Ra. (a) Ra is plotted against $\mathrm{Nu}$ for $4<R_{\rho}<4.5$ on double logarithmic scales. The thick solid line is the linear fit through the data, while the thin dashed line represents the parameterization by Kelley [1990] with a slope of 1/3. (b) Fit slopes determined as in Figure 9a for successive bins of $R_{\rho}$ of interval 0.5 within the range $1<R_{\rho}<10$. The circle represents the fit in Figure 9a. Error bars indicate bootstrapped 95\% confidence limits. (c and d) Identical to Figures $9 \mathrm{a}$ and $9 \mathrm{~b}$, respectively, but the heat flux in $\mathrm{Nu}^{*}$ is expressed as $F_{H, \mathrm{~mol}}=\left(c_{p} / \alpha\right) \mathrm{F}_{\rho, \mathrm{DS}, \mathrm{mol}} R_{F, \mathrm{Kel}}{ }^{-1}$.

$|\Delta \eta|=0.3$. Our finding of $\eta \approx 0.2$ is thus realistic and using $C\left(R_{\rho}\right)=\mathrm{NuRa}^{-0.2}$ instead of $C\left(R_{\rho}\right)=\mathrm{NuRa}^{-1 / 3}$ should result in a better collapse of the experimentally derived $C\left(R_{\rho}\right)$. Recently, an exponent $\eta<1 / 3$ in double-diffusive convection has gained some additional support from the three-dimensional direct numerical simulations of Flanagan et al. [2013]. However, it should be mentioned that they tested the exponent of equation (10) instead of equation (9) and thus ignored the dependence of $F_{H}$ on $H$.

[62] The parameterization of Kelley [1990] is based on $\eta=1 / 3$ which we have shown might not be the appropriate value. Figure 9a shows that this does not necessarily affect heat flux estimates. For $\mathrm{Ra}=\mathrm{Ra}_{\text {int }}=\mathrm{O}\left(10^{8}\right)$, where both lines in Figure 9a intersect, both Kelley [1990] and our estimate yield the same $\mathrm{Nu}$ and thus identical heat fluxes if applied to the same double-diffusive step. For $\mathrm{Ra}>\mathrm{Ra}_{\text {int }}$, however, $F_{H, \text { Kel }}$ overestimates and for $\mathrm{Ra}<\mathrm{Ra}_{\text {int }}$ underestimates the true heat fluxes. We suggest to correct heat fluxes by $F_{H, \text { corr }}=F_{H, \text { Kel }} \xi_{\text {corr }}$, where the correction factor $\xi_{\text {corr }}$ accounts for the choice of $\eta$ and is defined by equation (15) with $\mathrm{Ra}_{2}=\mathrm{Ra}_{\text {int }}$. In Figure $9 \mathrm{c}, \mathrm{Ra}_{\text {int }}$ is smaller than in Figure $9 \mathrm{a}$, because $F_{H}{ }^{*}$ depends on $R_{F, \text { Kel }}$ and at $4<R_{\rho}<4.5$, 

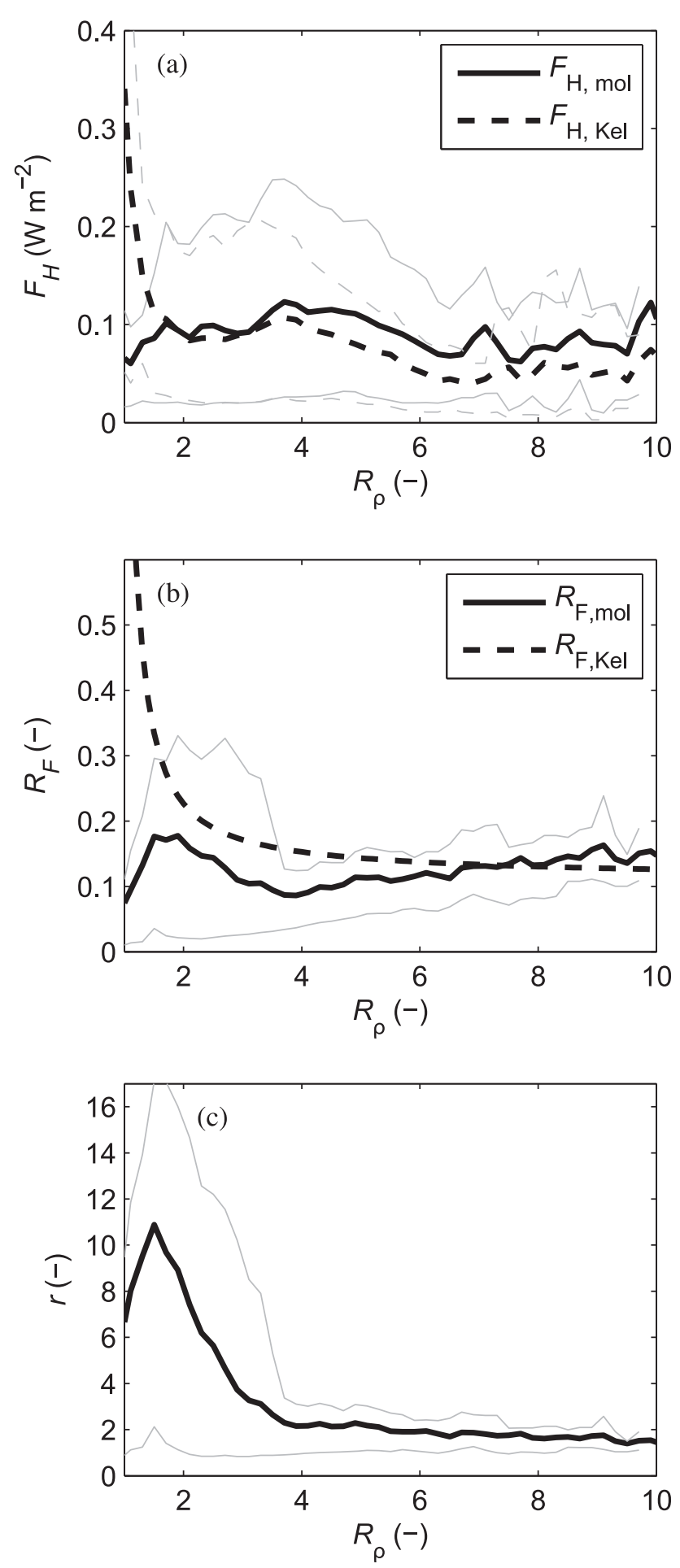

Figure 10. (a) Heat flux, (b) density flux ratio, and (c) interface thickness ratio as function of $R_{\rho}$. For all three panels, the Lake Kivu data set is subdivided into bins of $R_{\rho}$ of interval 0.4 with 0.2 overlap and for each bin we calculate the arithmetic mean (black lines) and the 10th and 90th percentiles (gray lines). In Figures $10 \mathrm{a}$ and $10 \mathrm{~b}$ the results from the Kelley [1990] parameterization are shown for comparison.
$R_{F, \text { Kel }}$ deviates from $R_{F, \text { mol }}$ by almost a factor of 2 , which offsets the solid line vertically. The slope $\eta^{*}$, however, is not affected by the choice of $R_{F}$ and is an independent estimate for the exponent $\eta$.

\subsection{Comparison to Kelley [1990]}

[63] In this section, we compare heat flux and density flux ratio estimates of Kelley [1990] to our measurements. In Lake Kivu, the average $\mathrm{Ra}=\mathrm{O}\left(10^{8}\right)$ (Figure 6h) and we thus expect good agreement between $F_{H, \mathrm{Kel}}$ and $F_{H \text {,mol }}$. The comparison is shown in Figure $10 \mathrm{a}$. Here $F_{H, \mathrm{Kel}}$ and $F_{H \text {,mol }}$ are calculated for each interface and arithmetic means (thick black lines) as well as 10th and 90th percentiles (thin gray lines) are shown bin-wise (interval of 0.4 , overlap 0.2 ) as a function of $R_{\rho}$. For $2<R_{\rho}<4$, the agreement is excellent confirming our expectation. For $R_{\rho}>4$, $F_{H, \text { Kel }}$ is $10-40 \%$ smaller than $F_{H, \text { mol }}$ and for small $R_{\rho}<2$ the molecular heat fluxes do not follow the increase of $F_{H, \text { Kel }}$. This is because at such small $R_{\rho}$, the molecular flux assumption breaks down. The arithmetic means of $F_{H, \mathrm{Kel}}$ and $F_{H, \mathrm{~mol}}$ are $0.09 \mathrm{~W} \mathrm{~m}^{-2}$ and $0.10 \mathrm{~W} \mathrm{~m}^{-2}$, respectively.

[64] In Figure $10 \mathrm{~b}$, we compare $R_{F, \text { mol }}$ from equation (14) to $R_{F, \text { Kel }}$ and in Figure 10c, $r$ is shown as a function of $R_{\rho}$. The bins of $R_{\rho}$ are identical to Figure 10a. For $6<R_{\rho}<10$, $R_{F, \text { mol }} \approx R_{F, \text { Kel }} \approx 0.15$, which is the value initially found by Turner [1965] for $R_{\rho}>2$, but slightly larger than $R_{F, \mathrm{LS}}=\tau^{1 / 2} \approx 0.10$. For $1<R_{\rho}<6, R_{F, \text { mol }}$ is smaller than $R_{F, \text { Kel }}$, because we only account for molecular transport through interfaces. Interfacial entrainment, which is included in $R_{F, \mathrm{Kel}}$, increases the transport of salt relative to heat and thus leads to a larger $R_{F}$. This is most evident for $R_{\rho}<2$, when $R_{F, \text { Kel }}$ steeply increases whereas $R_{F, \text { mol }}$ decreases. Another interesting feature is the different trends for $4<R_{\rho}<10$. While $R_{F, \text { Kel }}$ decreases, $R_{F, \text { mol }}$ increases with $R_{\rho}$ in a similar way as predicted by Newell [1984] and observed in the simulations by Carpenter et al. [2012a]. The increase of $R_{F \text {,mol }}$ (equation (14)) with $R_{\rho}$ is only possible because the decrease of $r$ with $R_{\rho}$ is very small (Figure 10c). The fit function chosen by Kelley [1990] does not allow for an increase of $R_{F}$ at large $R_{\rho}$. It was chosen to map the strong change of $R_{F}$ at small $R_{\rho}$, where most of the experimental data points were located [Kelley, 1990, Figure 2]. The observed increase of $R_{F}$ with $R_{\rho}$ at large $R_{\rho}$ is thus not in contradiction with the experimental data in Kelley [1990].

\subsection{Implications for Arctic Heat Fluxes}

[65] Vertical heat fluxes are of particular interest in the Arctic Ocean, where warm (and salty) water from the North Atlantic intrudes at a depth of 200-400 m [Carmack et al., 1997] with the potential of melting the overlying sea ice [Turner, 2010]. Double-diffusive staircases are found at the upper boundary of this intrusion. In Table 1, we summarize the staircase properties of four different locations within the Arctic Ocean, provide the literature estimates for $F_{H, \mathrm{Kel}}$ and $F_{H \text {,mol }}$, compute correction factors $\xi_{\text {corr }}$, and finally calculate the corrected heat fluxes $F_{H \text {,corr }}$. Even though each of the parameters in Table 1 varies by up to two orders of magnitude, we provide average values in order to simplify comparison.

[66] We discuss the Canada Basin (CB) [Timmermans et al., 2008] and the Beaufort Sea (BS) [Padman and Dillon, 1987] separately from the Amundsen Basin (AB) [Sirevaag 
SOMMER ET AL.: INTERFACE AND FLUX IN DOUBLE DIFFUSION

Table 1. Comparison of Staircase Properties and Heat Fluxes in the Arctic Ocean and Lake Kivu ${ }^{a}$

\begin{tabular}{|c|c|c|c|c|c|}
\hline Location & $\begin{array}{c}\text { Lake Kivu } \\
\text { [Sommer et al., 2013] }\end{array}$ & $\begin{array}{c}\text { Canada Basin } \\
\text { [Timmermans et al., 2008] }\end{array}$ & $\begin{array}{c}\text { Beaufort Sea } \\
\text { [Padman and Dillon, 1987] }\end{array}$ & $\begin{array}{c}\text { Amundsen Basin } \\
\text { [Sirevaag and Fer, 2012] }\end{array}$ & $\begin{array}{c}\text { Laptev Sea Slope } \\
\text { [Polyakov et al., 2012] }\end{array}$ \\
\hline Depth range (m) & $110-485$ & $200-300$ & $320-430$ & $200-260$ & $160-220$ \\
\hline$R_{\rho}(-)$ & $2.4-5.6$ & $2.0-7.0$ & $4.0-6.0$ & $2.2-3.8$ & $1.2-3.0$ \\
\hline$\Delta T(\mathrm{mK})$ & 11 & 40 & 10 & 65 & 300 \\
\hline$H_{T}(\mathrm{~m})$ & 0.7 & 2.5 & 1.5 & 1.3 & 15.0 \\
\hline$h_{T}(\mathrm{~m})$ & 0.09 & 0.11 & 0.07 & 0.73 & 2.79 \\
\hline$\alpha\left(\mathrm{K}^{-1}\right)$ & $2.6 \times 10^{-4}$ & $6.4 \times 10^{-5}$ & $6.4 \times 10^{-5}$ & $6.0 \times 10^{-5}$ & $6.0 \times 10^{-5}$ \\
\hline$v\left(\mathrm{~m}^{2} \mathrm{~s}^{-1}\right)$ & $9.1 \times 10^{-7}$ & $1.8 \times 10^{-6}$ & $1.8 \times 10^{-6}$ & $1.8 \times 10^{-6}$ & $1.8 \times 10^{-6}$ \\
\hline $\operatorname{Ra}(-)$ & $1 \times 10^{8}$ & $2 \times 10^{9}$ & $1 \times 10^{8}$ & $1 \times 10^{9}$ & $4 \times 10^{12}$ \\
\hline$\left(\mathbf{R a} / \mathbf{R a}_{\text {int }}\right)^{\Delta \eta}(-)$ & 0.98 & 0.68 & 1.01 & 0.71 & 0.24 \\
\hline$F_{H, \mathrm{~mol}}\left(\mathrm{~W} \mathrm{~m}^{-2}\right)$ & 0.10 & 0.20 & 0.09 & 0.05 & 0.06 \\
\hline$F_{H, \mathrm{Kel}}\left(\mathrm{W} \mathrm{m}^{-2}\right)$ & 0.09 & 0.22 & 0.06 & 0.60 & 8.00 \\
\hline$F_{H, \text { corr }}\left(\mathrm{W} \mathrm{m}^{-2}\right)$ & 0.09 & 0.15 & 0.06 & 0.43 & 1.95 \\
\hline
\end{tabular}

${ }^{\mathrm{a}}$ For all sites, we use $\mathrm{Ra}_{\text {int }}=10^{8}, \Delta \eta=(0.2-1 / 3), g=9.81 \mathrm{~m} \mathrm{~s}^{-2}$ and $\kappa_{T}=1.4 \times 10^{-7} \mathrm{~m}^{2} \mathrm{~s}^{-1}$. Note that $F_{H, \mathrm{Kel}}$ for Padman and Dillon [1987] and Timmermans et al. [2008] is based on the parameterization of Marmorino and Caldwell [1976] and not Kelley [1990]. However, for $4<R_{\rho}<8$ both parameterizations are almost identical and both use $\eta=1 / 3$. The bold row indicates the correction factor.

and Fer, 2012] and the Laptev Sea Slope (LS) [Polyakov et al., 2012] because of their difference in $R_{\rho}$ and the geographical separation by the Lomonosov Ridge. The staircase parameters and heat fluxes for CB and especially BS are surprisingly similar to Lake Kivu. Correction factors of 0.68 and 1.01 for $\mathrm{CB}$ and $\mathrm{BS}$, respectively, result in corrected heat fluxes of $F_{H \text {,corr }}=0.15 \mathrm{~W} \mathrm{~m}^{-2}$ and $0.06 \mathrm{~W} \mathrm{~m}^{-2}$ that agree with $F_{H, \text { mol }}$ within 50\%. Note that Turner [2010] used $F_{H, \text { Kel }}=0.22 \mathrm{~W} \mathrm{~m}^{-2}$ from CB for estimating the contribution of double-diffusive heat fluxes to the melting of Arctic sea ice. For $\mathrm{AB}$ and $\mathrm{LS}$, correction factors are 0.71 and 0.24 , respectively, corresponding to $F_{H \text {,corr }}=0.43 \mathrm{~W} \mathrm{~m}^{-2}$ and $1.95 \mathrm{~W}$ $\mathrm{m}^{-2}$. Even though the correction reduces $F_{H, \mathrm{Kel}}$ significantly, $F_{H \text {,corr }}$ for $\mathrm{AB}$ and LS is still much larger than $F_{H \text {,corr }}$ for $\mathrm{CB}$ and BS. Furthermore, $F_{H \text {,corr }}$ at $\mathrm{AB}$ and LS is 9 and 33 times larger than the corresponding estimate of $F_{H \text {,mol }}$, respectively. The large difference between $F_{H \text {,mol }}$ and $F_{H \text {,corr }}$ for AB and LS is not understood. One reason could be that $F_{H \text {,mol }}$ underestimates the total flux, because advective transport across interfaces becomes important at $R_{\rho}<2$. Another possibility is that the applied correction is not large enough, because the uncertainty in $\eta$ (Figure 9) increases for small $R_{\rho}$. However, exponents of $\eta=-0.65$ and -0.13 are needed for AB and LS, respectively, to reduce $F_{H, \mathrm{Kel}}$ to $F_{H \text {,mol }}$, and such small $\eta$ are not supported by our data. A third possibility is that the Earth's rotation reduces turbulent fluxes in the mixed layers [Kelley, 1987; King et al., 2009, 2012]. This effect is only important for interface thicknesses larger than a certain threshold that inversely depends on the Coriolis parameter. This condition is fulfilled for both LS and AB, but not for CB, BS, or Lake Kivu [Carpenter and Timmermans, 2013].

[67] In summary, we found that correcting heat fluxes for the choice of $\eta$ in equation (9) reduces heat flux estimates in the Arctic by up to a factor of four and levels the extreme variability of heat fluxes measured at different locations in the Arctic Ocean.

\section{Conclusion}

[68] We have presented the most detailed study of double-diffusive interfaces in a natural system to date. The
9401 interfaces used in this study were detected in Lake Kivu between $111 \mathrm{~m}$ and $451 \mathrm{~m}$ depth with most of the interfaces being located in the gradients between $180 \mathrm{~m}$ and $200 \mathrm{~m}$ as well as between $300 \mathrm{~m}$ and $330 \mathrm{~m}$ depth. Average interface thicknesses were $9 \mathrm{~cm}$ and $6 \mathrm{~cm}$ for temperature and dissolved substances, respectively, and $0.7 \mathrm{~m}$ for the mixed layers, with molecular heat fluxes through interfaces of $0.10 \mathrm{~W} \mathrm{~m}^{-2}$. The smallest observed interface thicknesses are $\sim 1 \mathrm{~mm}$ and $\sim 1 \mathrm{~cm}$ for dissolved substances and temperature, respectively.

[69] The larger interface thickness of temperature compared to dissolved substances confirms the boundary-layer structure of the interface as assumed by Linden and Shirtcliffe [1978]. The histogram of boundary-layer Rayleigh numbers has a long tail at small boundary-layer Rayleigh numbers, peaks at $\mathrm{O}\left(10^{2}\right)$ and continuously decreases between $\mathrm{O}\left(10^{2}\right)$ and $\left(10^{4}\right)$. The long tail confirms the idea of Linden and Shirtcliffe [1978] that the $T$ and DS interfaces periodically grow by molecular diffusion from initially the same thickness. However, the boundary-layer break-off does not occur at a single critical boundary-layer Rayleigh number.

[70] Heat flux estimates based on the parameterization of Kelley [1990] agreed well with molecular fluxes through interfaces, in particular for $2<R_{\rho}<4$. However, the Kelley [1990] parameterization should only be applied to doublediffusive systems with Rayleigh numbers $\mathrm{O}\left(10^{8}\right)$, similar to $\mathrm{Ra}$ in the laboratory experiments used by Kelley [1990]. For different Rayleigh numbers, the exponent $\eta$ in the scaling $\mathrm{Nu} \sim \mathrm{Ra}^{\eta}$ becomes important. We estimated $\eta=0.20 \pm 0.03$ for density ratios between 2 and 6 , which is different from $\eta=1 / 3$ as proposed by Turner [1965] and used by Kelley [1990]. We thus suggest to correct heat flux estimates based on the parameterization of Kelley [1990] by multiplication with the factor $\xi_{\text {corr }}=\left(\mathrm{Ra} / 10^{8}\right)^{(\eta-1 / 3)}$, where $\mathrm{Ra}$ is the Rayleigh number of the system of interest and $\eta$ is the true exponent.

[71] We studied the effect of this correction on heat flux estimates in the Arctic Ocean. There, double-diffusive staircases form at the upper boundary of the warm North Atlantic intrusion between $200 \mathrm{~m}$ and $500 \mathrm{~m}$ depth and the 


\section{SOMMER ET AL.: INTERFACE AND FLUX IN DOUBLE DIFFUSION}

heat flux through these staircases contributes to the melting of the Arctic sea ice [Turner, 2010]. For Arctic staircases, Rayleigh numbers are generally larger than $\mathrm{O}\left(10^{8}\right)$ and therefore $\xi_{\text {corr }} \leq 1$. This leads to up to four times smaller heat fluxes compared to previous estimates based on Kelley [1990].

[72] Acknowledgments. We thank Natacha and Tom Tofield Pasche for their hospitality and organizational support in Rwanda and Fidèle Kanamugire and his crew for their help on the lake. We also thank Michel Halbwachs for letting us use his float on the lake and Marc Chevalier for his practical assistance in Rwanda. The project was supported by the Swiss National Science Foundation under grant 200021-122183 and grant 200020-140538 (Lake Kivu-turbulence and double diffusion in permanent stratification).

\section{References}

Boehrer, B., S. Dietz, C. von Rohden, U. Kiwel, K. D. Jöhnk, S. Naujoks, J. Ilmberger, and D. Lessmann (2009), Double-diffusive deep water circulation in an iron-meromictic lake, Geochem. Geophys. Geosyst., 10, Q06006, doi:10.1029/2009GC002389.

Carmack, E. C., K. Aagaard, J. Swift, R. MacDonald, F. McLaughlin, E. Jones, R. Perkin, J. Smith, K. Ellis, and L. Killius (1997), Changes in temperature and tracer distributions within the Arctic Ocean: Results from the 1994 Arctic Ocean section, Deep Sea Res., Part II, 44(8), 1487-1502, doi:10.1016/S0967-0645(97)00056-8.

Carpenter, J. R., T. Sommer, and A. Wüest (2012a), Simulations of a double-diffusive interface in the diffusive convection regime, J. Fluid Mech., 711, 411-436, doi:10.1017/jfm.2012.399.

Carpenter, J. R., T. Sommer, and A. Wüest (2012b), Stability of a doublediffusive interface in the diffusive convection regime, J. Phys. Oceanogr., 42(5), 840-854, doi:10.1175/JPO-D-11-0118.1.

Carpenter, J. R., and M.-L. Timmermans (2013), Does rotation influence double-diffusive fluxes in polar oceans?, J. Phys. Oceanogr., doi: 10.1175/JPO-D-13-098.1.

Castaing, B., G. Gunaratne, F. Heslot, L. Kadanoff, A. Libchaber, S Thomae, X.-Z. Wu, S. Zaleski, and G. Zanetti (1989), Scaling of hard thermal turbulence in Rayleigh-Bénard convection, J. Fluid Mech., 204, 1-30, doi: $10.1017 / \mathrm{S} 0022112089001643$.

Chen, C. T., and F. J. Millero (1986), Precise thermodynamic properties for natural waters covering only the limnological range, Limnol. Oceanogr., 31(3), 657-662, doi:10.4319/10.1986.31.3.0657.

Descy, J.-P., F. Darchambeau, and M. Schmid (Eds.) (2012), Lake Kivu: Limnology and Biogeochemistry of a Tropical Great Lake, Aquatic Ecology Series 5, Springer, Dordrecht.

Fernando, H. J. S. (1989), Buoyancy transfer across a diffusive interface, $J$. Fluid Mech., 209, 1-34, doi:10.1017/S0022112089003010.

Flanagan, J. D., A. S. Lefler, and T. Radko (2013), Heat transport through diffusive interfaces, Geophys. Res. Lett., 40, 2466-2470, doi:10.1002/ grl.50440.

Foster, T., and E. C. Carmack (1976), Temperature and salinity structure in the Weddell Sea, J. Phys. Oceanogr., 6, 36-44, doi:10.1175/15200485(1976)006<0036:TASSIT $>2.0 . \mathrm{CO} ; 2$.

Griffiths, R. (1979), The transport of multiple components through thermohaline diffusive interfaces, Deep Sea Res., Part A, 26, 383-397, doi 10.1016/0198-0149(79)90052-9.

Grossmann, S., and D. Lohse (2000), Scaling in thermal convection: A unifying theory, J. Fluid Mech., 407, 27-56, doi:10.1017/ S0022112099007545.

Haynes W.M., Lide D.R. (2011), CRC Handbook of Chemistry and Physics. 92nd edition, CRC Press, Oxford.

Hoare, R. A. (1968), Thermohaline convection in Lake Vanda, Antarctica, J. Geophys. Res., 73(2), 607-612, doi:10.1029/JB073i002p00607.

Howard, L. N. (1966), Applied Mechanics, Proceedings of the Eleventh International Congress of Applied Mechanics Munich (Germany), edited by H. Görtler, pp 1109-1115, Springer-Verlag Berlin. DOI: 10.1007/ 978-3-662-29364-5_147.

Kelley, D. E. (1987), The influence of planetary rotation on oceanic double-diffusive fluxes, J. Mar. Res., 45(4), 829-841, doi:10.1357/ 002224087788327136 .

Kelley, D. E. (1990), Fluxes through diffusive staircases: A new formulation, J. Geophys. Res., 95(C3), 3365-3371, doi:10.1029/ JC095iC03p03365.
Kelley, D. E., H. J. S. Fernando, A. E. Gargett, J. Tanny, and E. Özsoy (2003), The diffusive regime of double-diffusive convection, Prog. Oceanogr., 56(3-4), 461-481, doi:10.1016/S0079-6611(03)00026-0.

Kerr, R. M. (1996), Rayleigh number scaling in numerical convection, $J$. Fluid Mech., 310, 139-179, doi:10.1017/S0022112096001760.

King, E. M., S. Stellmach, J. Noir, U. Hansen, and J. M. Aurnou (2009), Boundary layer control of rotating convection systems, Nature, 457(7227), 301-304, doi:10.1038/nature07647.

King, E. M., S. Stellmach, and J. M. Aurnou (2012), Heat transfer by rapidly rotating Rayleigh-Bénard convection, J. Fluid Mech., 691, 568582, doi:10.1017/jfm.2011.493.

Haynes, W.M., D.R. Lide (2011), CRC Handbook of Chemistry and Physics. 92nd edition, CRC Press, Oxford.

Linden, P. F. (1974), A note on the transport across a diffusive interface, Deep Sea Res. Oceanogr. Abstr., 21, 283-287, doi:10.1016/00117471(74)90099-0.

Linden, P. F., and T. G. L. Shirtcliffe (1978), The diffusive interface in double-diffusive convection, J. Fluid Mech., 87(3), 417-432, doi: 10.1017/S002211207800169X.

Marmorino, G., and D. Caldwell (1976), Heat and salt transport through a diffusive thermohaline interface, Deep Sea Res. Oceanogr. Abstr., 23(1), 59-67, doi:10.1016/0011-7471(76)90808-1.

Neal, V. T., S. Neshyba, and W. Denner (1969), Thermal stratification in the arctic ocean, Science, 166(3903), 373-374, doi:10.1126/ science.166.3903.373.

Newell, T. (1984), Characteristics of double-diffusive interface at high density stability ratios, J. Fluid Mech., 149, 386-401, doi:10.1017/ S0022112084002718.

Newman, F. C. (1976), Temperature steps in Lake Kivu: A bottom heated saline lake, J. Phys. Oceanogr., 6(2), 157-163, doi:10.1175/15200485(1976)006<0157:TSILKA $>2.0$. CO $; 2$.

Osborn, T. R. (1973), Temperature microstructure in Powell Lake, J. Phys. Oceanogr., 3(3), 302-307, doi:10.1175/1520-0485(1973)003<0302 TMIPL $>2.0 . \mathrm{CO} ; 2$.

Özsoy, E., and S. Besiktebe (1995), Sources of double diffusive convection and impacts on mixing in the Black Sea, in Geophysical Monograph No. 94, edited by A. Brandt and H. J. S. Fernando, pp. 261-274, AGU, Washington, D. C.

Padman, L., and T. Dillon (1987), Vertical heat fluxes through the Beaufort Sea thermohaline staircase, J. Geophys. Res., 92(C10), 10,799-10,806, doi:10.1029/JC092iC10p10799.

Padman, L., and T. Dillon (1989), Thermal microstructure and internal waves in the Canada Basin diffusive staircase, Deep Sea Res., Part A, 36(4), 531-542, doi:10.1016/0198-0149(89)90004-6.

Pasche, N., C. Dinkel, B. Müller, M. Schmid, A. Wüest, and B. Wehrli (2009), Physical and biogeochemical limits to internal nutrient loading of meromictic Lake Kivu, Limnol. Oceanogr., 54(6), 1863-1873, doi: 10.4319/1o.2009.54.6.1863

Polyakov, I. V., A. V. Pnyushkov, R. Rember, V. V. Ivanov, Y.-D. Lenn, L. Padman, and E. C. Carmack (2012), Mooring-based observations of double-diffusive staircases over the Laptev Sea slope, J. Phys. Oceanogr., 42(1), 95-109, doi:10.1175/2011JPO4606.1.

Ricker, W. E. (1973), Linear regressions in fishery research, J. Fish. Res. Board Can., 30(3), 409-434, doi:10.1139/f73-072.

Sánchez, X., and E. Roget (2007), Microstructure measurements and heat flux calculations of a triple-diffusive process in a lake within the diffusive layer convection regime, J. Geophys. Res., 112, C02012, doi: 10.1029/2006JC003750.

Schmid, M., and A. Wüest (2012), Stratification, mixing and transport processes in Lake Kivu, in Lake Kivu: Limnology and Biogeochemistry of a Tropical Great Lake, edited by J.-P. Descy, F. Darchambeau, and M. Schmid, pp. 13-29, Springer, Dordrecht.

Schmid, M., K. Tietze, M. Halbwachs, A. Lorke, D. McGinnis, and A. Wüest (2004), How hazardous is the gas accumulation in Lake Kivu? Arguments for a risk assessment in light of the Nyiragongo Volcano eruption of 2002, Acta Vulcanol., 14(1-2), 115-122.

Schmid, M., A. Lorke, C. Dinkel, G. Tanyileke, and A. Wüest (2004), Double-diffusive convection in Lake Nyos, Cameroon, Deep Sea Res., Part I, 51,1097-1111, doi:10.1016/j.dsr.2004.02.010.

Schmid, M., M. Halbwachs, B. Wehrli, and A. Wüest (2005), Weak mixing in Lake Kivu: New insights indicate increasing risk of uncontrolled gas eruption, Geochem. Geophys. Geosyst., 6(7), Q07009, doi:10.1029/ 2004GC000892.

Schmid, M., M. Busbridge, and A. Wüest (2010), Double-diffusive convection in Lake Kivu, Limnol. Oceanogr., 55(1), 225-238. 


\section{SOMMER ET AL.: INTERFACE AND FLUX IN DOUBLE DIFFUSION}

Schmitt, R. W. (1994), Double diffusion in oceanography, Annu. Rev. Fluid Mech., 26(1), 255-285, doi:10.1146/annurev.fl.26.010194.001351.

Shirtcliffe, T. G. L. (1973), Transport and profile measurements of the diffusive interface in double diffusive convection with similar diffusivities, J. Fluid Mech., 57(1), 27-43, doi:10.1017/S002211207300100X.

Sirevaag, A., and I. Fer (2012), Vertical heat transfer in the Arctic Ocean: The role of double-diffusive mixing, J. Geophys. Res., 117, C07010 doi:10.1029/2012JC007910.

Sommer, T., J. R. Carpenter, M. Schmid, R. G. Lueck, and A. Wües (2013), Revisiting microstructure sensor responses with implications for double-diffusive fluxes, J. Atmos. Oceanic Technol., 30(8), 1907-1923, doi:10.1175/JTECH-D-12-00272.1.

Sommeria, J. (1999), Turbulence: The elusive "ultimate state" of therma convection, Nature, 398(6725), 294-295, doi:10.1038/18572.

Stamp, A. P., G. O. Hughes, R. I. Nokes, and R. W. Griffiths (1998), The coupling of waves and convection, J. Fluid Mech., 372, 231-271, doi 10.1017/S0022112098002304.

Timmermans, M.-L., H. Melling, and L. Rainville (2007), Dynamics in the deep Canada Basin, Arctic Ocean, inferred by thermistor chain time series, J. Phys. Oceanogr., 37(4), 1066-1076, doi:10.1175/JPO3032.1.

Timmermans, M.-L., J. Toole, R. Krishfield, and P. Winsor (2008), Icetethered profiler observations of the double-diffusive staircase in the Canada Basin thermocline, J. Geophys. Res., 113, C00A02, doi: 10.1029/2008JC004829.
Turner, J. S. (1965), The coupled turbulent transports of salt and heat across a sharp density interface, Int. J. Heat Mass Transfer, 8, 759-767.

Turner, J. S. (1973), Buoyancy Effects in Fluids, Cambridge Univ. Press, Cambridge, U. K

Turner, J. S. (1985), Multicomponent convection, Annu. Rev. Fluid Mech. 17(1), 11-44, doi:10.1146/annurev.fl.17.010185.000303.

Turner, J. S. (2010), The melting of ice in the Arctic Ocean: The influence of double-diffusive transport of heat from below, J. Phys. Oceanogr., 40(1), 249-256, doi:10.1175/2009JPO4279.1.

Worster, M. G. (2004), Time-dependent fluxes across doublediffusive interfaces, J. Fluid Mech., 505, 287-307, doi:10.1017/ S0022112004008523

Wüest, A., G. Piepke, and J. D. Halfman (1996), Combined effects of dissolved solids and temperature on the density stratification of Lake Malawi, in The Limnology, Climatology and Paleoclimatology of the East African Lakes, edited by T. C. Johnson and E. O. Odada, pp. 183202, Gordon and Breach, New York.

Wüest, A., T. Sommer, M. Schmid, and J. R. Carpenter (2012), Diffusivetype of double diffusion in lakes-A review, in Environmental Fluid Mechanics: Memorial Volume in Honour of Prof. Gerhard H. Jirka, IAHR Monograph, edited by W. Rodi and M. Uhlmann, pp. 271-284, CRC Press, Karlsruhe, Germany.

Yuan-Hui, L., and S. Gregory (1974), Diffusion of ions in sea water and in deep-sea sediments, Geochim. Cosmochim. Acta, 38(5), 703-714. 